\title{
Gobernando para obtener resultados en un mundo globalizado y localizado*
}

\section{Introducción}

"El gobierno es el más frío de todos los monstruos — diga lo que diga miente - y todo lo que tiene lo ha robado."

F. Nietzche

Este trabajo trata tres materias que resultan complementarias a la hora de producir una gobernabilidad (governance) receptiva y responsable en los países en desarrollo, principalmente la globalización, la localización y una gestión y una evaluación orientada a la obtención de resultados. La primera de estas materias reconoce las interdependencias en un mundo interconectado y discute cómo estas influencias deben dar forma a las sociedades tanto internas como transnacionales. La segunda materia concierne a las realineaciones del sector público dentro de las naciones para hacer frente a los retos asociados con las elevadas expectativas de una ciudadanía informada. La tercera de estas materias está relacionada con la creación de una nueva cultura de gobernabilidad (governance) que sea receptiva y responsable frente a los ciudadanos.

La globalización, la revolución de la información y la localización están ejerciendo una gran influencia en la gobernabilidad (governance) económica, tanto en el mundo industrializado, como en el mundo en vías de industrializarse. Con la globalización, cada vez resulta más evidente que "los Estados-nación son demasiado pequeños para hacer frente a cuestiones esenciales de la vida, y demasiado grandes para afrontar cuestiones menores." De forma más sencilla, los Estados-nación pierden con rapidez el control de alguno de aquellos ámbitos que eran objeto
Anwar Shah es economista de Banco Mundic

Contato:

ashah@ worldbank.org

*Artigo publicado na Revista Gestió y Análisis de Políticas Públicas, nº 16 septiembrodiciembre de 1999. 
tradicionalmente de control y regulación, como el comercio exterior, las telecomunicaciones y las transacciones financieras. La globalización también está provocando que pequeñas economías abiertas resulten vulnerables frente a los deseos de las grandes hedge funds $\mathrm{y}$, además, polariza la distribución de ingresos en favor de los trabajadores más habilidosos, extendiéndose así las disparidades entre ingresos. Con la revolución de la información, los gobiernos están experimentando una disminución del control sobre su capacidad para controlar el flujo de bienes y servicios, ideas y productos culturales. La localización también está llevando simultáneamente a una adquisición de poder (empowerment) en ciertas áreas, a la vez que se produce un fortalecimiento de élites locales en otras áreas. La gestión y la evaluación orientada a la obtención de resultados (Results Oriented Management and Evaluation - ROME) está enfrentando a la cultura burocrática y política con el modelo del ciudadano/ cliente y la responsabilidad (accountability) por los resultados. Este trabajo analiza los potenciales y los peligros asociados con el impacto de estos grandes cambios en la estructura de gobernabilidad en el siglo XXI. Más aún, obtiene lecciones de esta experiencia para capitalizar este importantísimo cambio y producir una mejora en la gobernabilidad (governance) del sector público en los países en desarrollo.

\section{Especiales retos que surgen a raíz de la globalización}

La globalización representa la transformación del mundo en un espacio compartido a través de conexiones globales en la economía, la política, la tecnología, las comunicaciones y el Derecho. Esta interconexión global supone que sucesos que tienen lugar en una parte del mundo pueden tener profundos efectos en el resto del mundo. Tal tipo de conexiones introducen una creciente separación de la producción respecto de la manufacturación y de los servicios respecto de la localización, un aumento de la permeabilidad de las fronteras y una reducción de la influencia de los instrumentos de política nacional. La creciente internacionalización de la producción ha separado a las compañías de la dotación de factores de cualquier nación individual. Drucker (1986: 21) puso de manifiesto tres separaciones de la política global (ver también Courchene, 1993):

- El sector primario se ha desgajado de la economía industrial.

- Dentro del mismo sector industrial, la producción se ha desgajado del empleo.

- Los movimientos de capital, más que el comercio de bienes y servicios, se han convertido en los motores y la fuerza que conduce la economía mundial. 
A medida que la globalización avanza, se está introduciendo un gran cambio que pone de manifiesto la fragilidad de los sistemas existentes de gobernabilidad(governance) global. Ésta, está, a su vez, impactando de forma adversa a los Estados de bienestar nacionales que tienen incentivos unidos a la producción nacional. La amplia magnitud de este cambio social y económico hace difícil que los gobernantes y los ciudadanos se enfrenten a sus consecuencias, especialmente aquellas naciones e individuos cuya suerte cambie como resultado de este cambio. En los siguientes apartados, discutiremos las consecuencias de este gran cambio para la gobernabilidad dentro de las naciones.

\section{Declive del Estado-nación, surgimiento de regímenes supranacionales y fortalecimiento de la localización}

La globalización como actividad económica presenta especiales retos para la asignación constitucional dentro de las naciones. Con la globalización, resulta evidente que de forma creciente las naciones-Estado son "demasiado pequeñas para hacer frente a importantes cuestiones de la vida y demasiado grandes para hacer frente a cuestiones menores." Strange (1996) argumenta que "das fuerzas impersonales de los mercados mundiales son ahora más poderosas que los Estados a los que se supone que en último término pertenece la máxima autoridad sobre la sociedad y la economía... ese declive de la autoridad de los Estados se pone de manifiesto en la creciente difusión de autoridad a otras instituciones y asociaciones, y a los cuerpos locales y regionales" (ver Held et al., 1999: 3). De forma más sencilla, los Estadosnaciones están rápidamente perdiendo el control sobre alguna de las áreas sobre las que ejercían el control y la regulación de forma tradicional, como la regulación del comercio exterior, la política de competencia, las telecomunicaciones y las transacciones financieras. Los gobiernos nacionales están experimentando una pérdida de control en su habilidad, para regular y/o controlar el flujo de bienes y servicios, ideas y productos culturales. Por ejemplo, en el Asia Oriental la crisis financiera manifestó un comportamiento por parte de las instituciones financieras y de las hedge funds que podían haber sido objeto de ponderación regulacional dentro de las naciones-Estado. El papel de las grandes hedge funds a la hora de desestabilizar el dinero nacional en circulación y prestar a actuaciones de instituciones bancarias de países industrializados a instituciones financieras indonesias en el período de la precrisis con insuficiente garantía para préstamos, sirven como sorprendente ejemplo de prácticas que no habrían sido permitidas en transacciones internas dentro de una nación-Estado (ver Whalley, 1999). De forma similar, en la mayoría de los países en desarrollo, una realzada movilidad de capital limita la capacidad del gobierno para gravar los ingresos de capital, 
especialmente en presencia de una feroz competencia para atraer la inversión extranjera directa. Gravar los ingresos de capital es algo que cada vez se constriñe más, debido a la falta de habilidad para descubrir las transacciones transfronterizas. Por ejemplo, resultaría difícil para el gobierno de Japón gravar los ingresos de un corredor de bolsa que hace negocios con el comercio de valores británico en el mercado de bolsa belga. También se están expandiendo las oportunidades para las multinacionales de dedicarse a la transferencia de precios para limitar las responsabilidades impositivas. Mientras que el comercio por Internet ha estallado, atraer estas actividades al ámbito del impuesto resulta una tarea difícil incluso para los países industrializados. Así, la habilidad de los gobiernos para financiar los bienes públicos, especialmente aquellos de naturaleza redistributiva, puede verse debilitada a medida que el acceso a impuestos progresivos sobre ingresos (impuestos sobre los ingresos de personas físicas y jurídicas) se ve reducido, mientras que su acceso a impuestos de consumo general (VAT) mejora con la liberalización de la economía y la integración global. La posible erosión de la capacidad tributaria de los gobiernos a través de la globalización y de la competencia en los impuestos puede considerarse como un cambio bienvenido para los ciudadanos de países con pobres resultados en la actuación del sector público a la hora de proveer servicios públicos, como es el caso en la mayor parte de los países desarrollados. La globalización implica que ya no mucho es "extranjero" y que las sociedades transfronterizas "sin patria" homeless - tienen la habilidad de evadir los regímenes regulacionales de su país huésped y de su país natal. Estas dificultades están abriendo camino al surgimiento de instituciones especializadas de gobernabilidad (governance) global tales como la Organización Mundial del Comercio, y la Global Environmental Facility, con muchas otras que seguirán, especialmente instituciones que regulen la información tecnológica, las comunicaciones vía satélite y las transacciones financieras internacionales. Para los países que se enfrentan con una situación de crisis económica y que buscan apoyo internacional, incluso en áreas de política económica tradicional, está en alza el objetivo de desarrollo financiero internacional para influir en la toma de decisiones a nivel local. La globalización está, por tanto, desgajando la relación entre la soberanía, la territorialidad y el poder del Estado (ver Ruggie, 1993). Esta transformación supone que la gobernabilidad (governance) y la autoridad se difuminarán con múltiples centros dentro y más allá de la naciónEstado. De esta forma, las naciones-Estado se confederalizarían en los años venideros y abandonarían sus responsabilidades en estas áreas en favor de las instituciones supranacionales. 


\section{La revolución de la información y la adquisición de poder (empowerment) de los ciudadanos}

Con la revolución de la información, "la capacidad para recopilar, analizar y transmitir datos, y para coordinar actividades a nivel mundial ha aumentado de forma importante, mientras que el coste de hacerlo ha caído dramáticamente" (Lipsey, 1997: 76). Las sociedades tienen ahora la capacidad de "repartirse la cadena del valor añadido" (Krugman, 1995) para alcanzar competitividad internacional. La revolución de la información otorga poder a los ciudadanos para acceder, transmitir y transformar la información mediante fórmulas ante las que los gobiernos se encuentran sin fuerzas para poder bloquearlas y en este proceso se debilitan los controles de la autoridad. También se constriñe la habilidad de los gobiernos para mantener información fuera del alcance de los ciudadanos. La globalización de la información — televisión satélite, Internet, teléfono, fax — también sirve para realzar la conciencia de los ciudadanos acerca de sus derechos, obligaciones, opciones y alternativas y fortalece la demanda tanto de traspaso (del poder a la gente) como de localización de la toma de decisiones. La soberanía del consumidor y la adquisición de poder de los ciudadanos a través de coaliciones internacionales en áreas específicas funciona como contrapeso al capital global. La influencia de tales coaliciones es especialniente importante en cuestiones medioambientales tales como grandes pantanos y la industria de las focas.

\section{La soberanía del consumidor y el déficit de democracia}

En la emergente economía mundial sin barreras, los intereses de los residentes como ciudadanos son en ocasiones opuestos a sus intereses como consumidores. Esto se debe a que la internacionalización de la producción da poderes a los ciudadanos como consumidores, a la vez que los estándares de actuación son fijados por el mercado más que por los burócratas. Les desautoriza como ciudadanos votantes en la medida en que su acceso a la toma de decisiones está aún más restringido, ya que los centros de decisiones en los sectores tanto públicos como privados se mueven más allá de la nación-Estado, creando así un déficit democrático. Por ejemplo, un ciudadano en un mundo globalizado no tiene participación directa en la toma de decisiones vitales que afectan a su bienestar y que se adoptan en el cuartel general, bien de las agencias supranacionales y regímenes tales como el Fondo Monetario Internacional, el Banco Mundial, bien la Organización Mundial del Comercio o sociedades transnacionales como Coca-Cola o McDonald's. De forma similar, el Parlamento de la 
Unión Europea sólo es indirectamente responsable frente a los ciudadanos de Europa. A la hora de asegurar sus intereses como consumidores en la economía mundial, los individuos buscan cada vez más la localización y regionalización de la toma de decisiones para salvaguardar mejor sus intereses.

\section{Internacionalización de las ciudades y de las regiones}

Con una mayor movilidad de capital y una relajación del ambiente regulador respecto de la inversión directa extranjera, los gobiernos locales como proveedores de servicios relacionados con infraestructura, servirían más adecuadamente a los gobiernos nacionales, como canales para atraer tales inversiones. A medida que las fronteras se permeabilizan, se espera que las ciudades reemplacen a los países en las alianzas económicas transnacionales, a medida que las personas en Europa están descubriendo que los gobiernos nacionales tienen cada vez menos relevancia en sus vidas. Así, cada vez están más dispuestos a unir sus identidades y alianzas a ciudades y regiones. Por ejemplo, la alianza de Alpine Diamond que une Lyon con Ginebra y Turín, se ha convertido en un símbolo de uno de los esfuerzos más ambiciosos de Europa para romper las fronteras de la nación-Estado y dar forma a un nuevo destino político y económico.

\section{Conocimiento y competitividad internacional}

Con la movilidad de capital y otros flujos, son las habilidades, más que la entrega de recursos, las que de forma creciente determinan la competitividad internacional. El empleo cualificado en los servicios "simbólico-analíticos" (Reich, 1991) identifica servicios como servicios de resolución de problemas, identificación de problemas y corretaje estratégico) se cualifica para ser tratado como capital más que como empleo. Courchene (1996) argumenta que para que los recursos mantengan su importancia deben comprender el conocimiento o técnicas de alto valor añadido. Estos desarrollos implican que incluso economías ricas en recursos deben efectuar una transformación a economías basadas en capital humano y que la política social ya no se distingue de la política económica. Sin embargo, típicamente la educación y el adiestramiento es responsabilidad de los gobiernos subnacionales. Por ello, sería necesario realinear esta responsabilidad dando al gobierno nacional un mayor papel en la mejora de las habilidades. El nuevo ambiente económico también polarizará la distribución de ingresos en favor de los trabajadores cualificados acentuando las desigualdades en los ingresos y posiblemente erradicando a las clases con ingresos medios bajos. Dado que los gobiernos nacionales pueden no disponer de medios para hacer frente a los fallos de 
la política social, los gobiernos subnacionales, trabajando conjuntamente con los gobiernos nacionales, tendrían que idear estrategias para hacer frente a la emergente crisis de la política social.

\section{Una potencial fuente de conflicto dentro de las naciones}

Los acuerdos de comercio internacional comprenden típicamente provisiones de política medioambiental y social. Pero estas políticas son típicamente responsabilidad de los gobiernos subnacionales. Ésta es una emergente área de conflicto entre los diferentes niveles de gobierno, ya que las decisiones nacionales en materia de relaciones internacionales afectan al balance de poderes dentro de las naciones. Para evitar estos conflictos, un principio que sirve como guía debería ser el de que, en la medida en que estos acuerdos comprenden previsiones de política social y de medio ambiente local, deben ser objeto de ratificación por parte de los gobiernos subnacionales tal y como se hace en la actualidad en Canadá.

\section{Reorientando al Estado como contrapeso a la globalización}

El avance de la globalización ha creado un vacío en el ambiente regulacional y ha debilitado la habilidad de las pequeñas economías abiertas para hacer frente a impactos externos (Rodrik, 1997). Tales impactos externos conducen típicamente a una importante influencia destructora sobre las redes de seguridad social sobre la distribución de ingresos y la incidencia de la pobreza, tal y como se ha presenciado recientemente en la crisis de Asia Oriental. Esto conduce a una creciente demanda del uso del gasto público, especialmente para la protección social y la redistribución. La globalización ha dotado de poder a los trabajadores cualificados para alcanzar una mayor remuneración. Courchene (1993) ha argumentado que esto provocará que los sueldos de los trabajadores no cualificados bajen a un índice salarial "máximo global" a medida que son reemplazados por trabajadores más baratos en otros sitios. Las sociedades pueden recurrir al dumping social; así, por ejemplo, la reducción del ingreso de garantía y el beneficio de la red de seguridad social sirven como soporte para mantener la competitividad internacional. Esto ejerce mayor presión sobre el sector público para la protección social. El trabajo empírico de Rodrik (ver Rodrik, 1998) para los países de la OCDE provee de algun apoyo a este punto de vista al descubrir él que la liberalización económica estaba favorablemente asociada con la seguridad social y los gastos del Estado social. El creciente hueco en los salarios de los trabajadores cualificados frente a los no cualificados que surge de la globalización 
tiene el potencial para la bipolarización de los salarios y la desaparición de

la clase media baja. Así, Rodrik (1997) ha avisado que la desintegración social resultante erosionará en último término el consenso doméstico en favor de mercados abiertos, hasta el punto de que se podría estar ante un resurgimiento del proteccionismo a nivel mundial. En respuesta a la reciente crisis financiera, en varios países se han observado algunos cambios en la liberalización económica. Algunos gobiernos de países en desarrollo han tratado de desalentar estos impactos introduciendo controles de capital (por ejemplo, Malasia) y tratando de fortalecer las redes de seguridad social con apoyo internacional (por ejemplo, Indonesia y Tailandia). En la actualidad se está debatiendo el papel de las agencias supranacionales a la hora de hacer frente a la política de competencia, regulando los movimientos de capital a corto plazo y controlando las actividades de los hedge funds.

La revolución de la información puede que también permita a los gobiernos nacionales prestar más atención a las necesidades de sus ciudadanos y limitar las demandas a favor de la descentralización. Esto se debe a que la revolución de la información está conduciendo a un descenso en los costes de transacción y, por tanto, está reduciendo los costes para corregir las asimetrías en la información y a una mejoría en la redacción y ejecución de los contratos (ver Eid, 1996). Hart (1995) ha argumentado que un mundo así de organizacional resulta menos importante y, por tanto, como consecuencia de ello, se disminuye la necesidad de instituciones descentralizadas.

Como conclusión, la globalización no implica en absoluto el fallecimiento del Estado-nación, sino más bien la reorientación del Estado-nación para hacer frente a una estructura de gobernabilidad (governance) más compleja de un mundo interconectado. Puede que incluso los líderes de algunos países visualicen un papel más activo del Estado a la hora de igualar las ruedas de los mercados de capital global para enfrentarse con fallos en la política social y económica tal y como se ha experimentado en el Asia Oriental.

\section{Retos de especial trascendencia que surgen de la localización}

Un número amplio y creciente de países por todo el globo están reexaminando los papeles de los diversos niveles de gobierno y su asociación con el sector privado y con la sociedad civil con vistas a crear gobiernos que funcionen y sirvan a su gente (ver Shah, 1998, para motivaciones para tal cambio). Por encima de todo, el impulso de estos cambios pone de manifiesto una tendencia, bien hacia el traspaso 
(adquisición de poder de la gente) o hacia la localización (descentralización). La localización de la autoridad ha resultado ser una propuesta controvertida. Esto se debe a que la localización está siendo percibida tanto como una solución a los problemas tales como un sector público bifuncional, carencia de voz y salida (voice and exit), a la vez que como una fuente de nuevos problemas tales como la captura de una élite local, la agravación de la gestión microeconómica debido a la falta de disciplina fiscal y al comportamiento fiscal perverso de las unidades subnacionales. También existen dificultades conceptuales a la hora de elegir manteniendo el equilibrio, tal y como se discute en los siguientes párrafos (ver Boadway, Roberts y Shah, 1994, para más detalles).

\section{Cuestiones conceptuales}

La elección del grado de centralización frente a localización en el lado del gasto, y los medios precisos a través de los cuales los gobiernos centrales alcanzan su deseada influencia, variará de un tipo de gasto a otro. Implicará una compensación entre el beneficio de localización, que incluye el abastecimiento de las preferencias locales, la capacidad de proveer servicios a bajo coste y crear incentivos para innovar, en oposición al beneficio de la centralización, que incluye la preservación del mercado interno común, el logro de la igualdad nacional, la internacionalización de los derrames interestatales y la provisión de productos y servicios públicos nacionales. Distintos observadores y distintas sociedades tendrán diferentes puntos de vista acerca del balance ideal y de las formas en que los trade-off pueden superarse. En el ámbito fiscal, mientras la responsabilidad fiscal dispone que la responsabilidad impositiva sea descentralizada para permitir a los gobiernos subnacionales la posibilidad de financiar al menos algunos de sus gastos, esta descentralización conlleva necesariamente desigualdades e ineficiencias. La magnitud de éstas es mayor cuanto mayor sea el grado de descentralización. Puede que la solución a esto esté en parte en retener el control de la estructura impositiva en manos del gobierno nacional. Esto conducirá a una mayor armonización del sistema impositivo entre los distintos niveles de gobiernos, contribuyendo así a la eficiencia de la economía nacional y reduciendo los costes de la recaudación de impuestos. También facilitará la búsqueda de objetivos redistributivos por parte del gobierno nacional a través del sistema tributario. Por otro lado, el gobierno nacional puede deshacer algunas de las ineficiencias y desigualdades de sistemas de impuestos y de gastos descentralizados a través del uso de transferencias fiscales a los gobiernos subnacionales. Esto resultará especialmente cierto respecto de las ineficiencias y desigualdades que surjan de las diferencias en los beneficios de la red fiscal a lo largo de las unidades subnacionales. 
En general, el papel del gobierno nacional en relación con los gobiernos subnacionales se predica sobre la provisión de bienes y servicios públicos nacionales, el mantenimiento de la eficiencia del mercado interno común y la búsqueda de la igualdad redistributiva por toda la nación. La importancia de esta última determina en gran medida el grado de centralización de una nación. Los objetivos de igualdad ejercen influencia sobre el papel que el gobierno nacional debería asumir en el sistema tributario directo y en el sistema de transferencias. También tienen influencia sobre el interés del gobierno nacional en proporcionar bienes y servicios cuasi-privados, tales como la educación y la salud, muchos de los cuales sirven al objetivo redistributivo. Y el interés del gobierno nacional en la igualdad afecta a su uso del sistema de transferencias intergubernamental para ejercer influencia sobre cómo se comportan los gobiernos subnacionales y para resdistribuir de forma igualitaria los recursos entre las jurisdicciones subnacionales. En otras palabras, el alcance del papel del gobierno nacional está en gran parte determinado por su interés o falta de interés en cuestiones redistributivas (ver Shah, 1994, para un sistema y unas líneas generales para alcanzar una asignación óptima de responsabilidades).

Más allá de estas cuestiones conceptuales, existe un número de consideraciones prácticas que tienen importancia en la búsqueda del equilibrio de la nación. Éstas incluyen el nivel de participación popular en elecciones generales, políticas feudales, la cultura del funcionariado y los incentivos, la gobernabilidad (governance) y la estructura de responsabilidad y las capacidades de los gobiernos locales.

\section{Retos prácticos del diseño institucional}

La localización trae consigo nuevos retos en el diseño institucional y en el desarrollo para hacer frente a: (a) la frágil gobernabilidad (governance), al haber asimetrías políticas y constitucionales; (b) asegurar la unión económica; (c) asegurar la disciplina fiscal bajo un federalismo de valerse por sí mismo, y (d) los incentivos políticos y burocráticos y la cultura de dirección y control y búsqueda de rentas. Estas cuestiones son brevemente discutidas en los siguientes párrafos.

a) Frágil gobernabilidad (governance) y asimetrías políticas e institucionales

La estructura de gobernabilidad sigue siendo frágil en muchas partes del mundo. Esto explica el surgimiento de más de 50 países nuevos desde la Segunda Guerra Mundial. La asimetría política surge de la asunción de un status desigual por parte de una unidad de la federación debido al volumen de población o a la base económica o el carácter étnico de su población. Para superar esta desigualdad, se han intentado diversas soluciones. Éstas 
incluyen un nuevo trazado de las fronteras tal y como ha ocurrido en diver-

sas ocasiones en la breve historia de Pakistán; creando una segunda Cámara con igual representación de sus unidades miembro (el Senado estadounidense) o igual representación de los gobiernos miembros (como en Alemania y en RSA); y estableciendo programas de igualación fiscal formal (como en Australia, Canadá y Alemania). A esto cabe añadir las soluciones constitucionales que otorgan cada vez más poderes centrales en algunas unidades (por ejemplo, la provisión del gobierno presidencial en la Constitución india), aumento de la autonomía regional para algunos (como para la región de Cataluña en España y de los Estados de Sabah y Sarawak en la Federación de Malasia); también se ha intentado la asimetría de facto, aunque saliendo y entrando como en el caso de Canadá y, a través de acuerdos bilaterales, como en la Federación rusa.

En esta cuestión, Pakistán representa un ejemplo interesante. La asimetría política ha sido siempre una fuente de tensión en Pakistán y, en respuesta a ello, se han vuelto a trazar las fronteras de forma periódica. En el momento de su nacimiento, el país estaba dividido en cinco provincias con Pakistán Oriental como la primera de ellas con una cuota de población del 54\%. En 1961, cuatro provincias del Pakistán Occidental se anexionaron en una unidad para compensar la posición dominante de Pakistán Oriental. Una unidad se dividió seguidamente con la caída de la dictadura militar. En 1971, la mayor parte de la provincia (Pakistán Oriental — hoy Bangladesh - ) se vio forzada a separarse, ya que el partido dominante de Pakistán Oriental llamado Liga Awani ganó por mayoría en las elecciones parlamentarias, pero no se le permitió formar gobierno. Incluso ahora desde que Punjab lidera la mayor parte de la población, su tamaño no le conduce a un diálogo entre iguales en la federación. Más aún, las fronteras de las provincias en Pakistán únicamente representan el legado del Imperio Británico y, por tanto, sirven sólo como fuente de conflicto y de polarización de las opiniones públicas. Para reducir estas tensiones, puede muy fácilmente suceder que Pakistán se vea obligada a volver a trazar las fronteras internas en el futuro tirando abajo el tamaño de las provincias existentes, quizas siguiendo la línea representada por las diversas divisiones administrativas.

\section{b) Asegurando la unión económica}

En un sistema federal existen diversas dimensiones del aseguramiento de la unidad económica que tienen relevancia para la gobernabilidad (governance) macroeconómica: la preservación del mercado común interno; la armonización fiscal; las transferencias y la seguridad social; las transferencias intergubernamentales y la equidad fiscal regional. Estas cuestiones son brevemente discutidas en los siguientes párrafos. 
La preservación del mercado común interno sigue siendo un área importante de preocupación para la mayor parte de las naciones que llevan a cabo la descentralización. En la búsqueda de atraer empleo y capital los gobiernos subnacionales pueden incurrir en políticas de "mendigar a sus vecinos" (beggar-thy-neighbour policies) y, en el proceso de hacerlo, levantar barreras a la movilidad de bienes y factores. De esta forma, la descentralización de las funciones reguladoras del gobierno crea un potencial de relaciones económicas desequilibradas entre las unidades subnacionales. De esta forma, la regulación de la actividad económica, tal como la regulación del comercio y la inversión, se deja con cáracter general mejor al gobierno federal/central. Sin embargo, debe señalarse que puede que los propios gobiernos centrales asuman políticas que redunden en detrimento del mercado interno común. Por tanto, tal y como sugirió Boadway (1992), las garantías constitucionales para el flujo libre de bienes y servicios pueden resultar ser la mejor alternativa para asignar únicamente al centro las responsabilidades reguladoras.

La Constitución indonesia contiene una cláusula de libre comercio y movilidad. Pero en la mayor parte de los países en desarrollo, el mercado interno común se encuentra impedido tanto por las políticas de los gobiernos subnacionales apoyados por el centro, como por los impedimentos formales e informales al empleo y a la movilidad de capital. Por ejemplo, en India y en Pakistán, los gobiernos locales confían en el impuesto sobre el comercio intermunicipal (octroi tax) como fuente predominante de los ingresos del Estado. En China, la libertad de establecimiento individual se ve fuertemente constreñida por la operación del sistema hukou de registro de domicilios que se utiliza para determinar la elegibilidad de las raciones de grano, el empleo, la vivienda y la seguridad social.

\section{La armonización tributaría y la coordinación}

La competencia tributaria entre jurisdicciones puede resultar beneficiosa al alentar la responsabilidad coste-efectividad en gobiernos locales y provinciales. Puede también por sí misma conducir a un cierto grado de armonización tributaría. Al mismo tiempo, las políticas tributarías descentralizadas pueden ocasionar ciertas ineficiencias y desigualdades en la federación, al igual que llevar a costes administrativos excesivos. La armonización tributaria trata de preservar los mejores rasgos de la descentralización tributaria a la vez que intenta evitar sus desventajas.

Las ineficiencias debidas a la toma de decisiones descentralizadas pueden producirse de múltiples formas. Para empezar, los Estados pueden implementar políticas que discriminen a los ciudadanos de otros Estados y negocios de otros Estados frente a los de los suyos. También pueden llevar a cabo políticas de "mendigar al vecino" (beggar-thy-neighbour), tratando 
así de atraer la actividad económica de otros Estados. La ineficiencia también puede ocurrir simplemente debido al surgimiento de distorsiones surgidas de diferentes estructuras tributarias elegidas de forma independiente por los gobiernos estatales sin ningún objetivo estratégico en mente. Las ineficiencias también pueden producirse si los sistemas tributarios estatales adoptan diferentes convenciones para hacer frente a los negocios (y a los residentes) que operan en más de una jurisdicción al mismo tiempo. Esto puede conducir a la doble imposición de algunas formas de ingresos y la no imposición de otras. Los sistemas tributarios estatales también pueden introducir desigualdades, ya que la movilidad de las personas podría alentarles a abandonar la progresividad. Es probable que los costes administrativos sean excesivos en un sistema tributario descoordinado (ver Boadway, Roberts y Shah, 1994). De esta forma, la armonización y coordinación contribuyen a lograr la eficiencia del mercado común interno, reducen los costes de la recaudación y acatamiento y ayudan a alcanzar los estándares nacionales de igualdad.

3. Pagos por medio de transferencias y seguridad social

Junto con el abastecimiento de bienes y servicios públicos, los pagos mediante transferencias a personas y negocios comprenden la mayor parte de los gastos del gobierno (especialmente en los países industrializados). Algunas de estas transferencias tienen objetivos de carácter redistributivo en sentido ordinario, y algunos tienen objetivos de política industrial o de desarrollo regional. Algunos de ellos son también para la redistribución en sentido de la seguridad social, tales como la pensión por desempleo, la seguridad médica y las pensiones de la seguridad social. Varios factores influyen en la asignación de responsabilidad para las transferencias. En el caso de transferencias a negocios, muchos economistas argumentarían que para empezar no deberían utilizarse. Pero, dado que sí lo son, es más probable que sean distorsionadoras si se utilizan a nível provincial que si se utilizan a nivel federal. Esto se debe a que el objetivo de los subsidios es típicamente el de aumentar las inversiones de capital por parte de sociedades, que se caracterizan por su movilidad geográfica. En cuanto a las transferencias individuales, al tener la mayoría de ellas objetivos de carácter redistributivo, su asignación gira en torno al grado en que el nivel federal del gobierno asume responsabilidad principal a favor de la equidad. Desde un punto de vista económico, las transferencias no son más que impuestos negativos directos. Uno puede argumentar que las transferencias deberían ser controladas por el mismo nivel del gobierno que controle los impuestos directos, de tal forma que puedan ser integrados para alcanzar objetivos de igualdad y armonizados a lo largo de la nación para lograr objetivos de eficiencia. El caso de la integración a nivel central se realza cuando uno reconoce los diversos tipos de transferencias que pueden 
existir para afrontar diferentes dimensiones de la equidad y de la seguridad social. También se deriva una ventaja de coordinar las pensiones por desempleo con el sistema tributario sobre ingresos o las pensiones con el pago a los pobres. Las transferencias descentralizadas a individuos a las provincias puede probablemente conducir a ineficiencias en el mercado común interno, a desigualdades fiscales y políticas interjurisdiccionales de "mendigar al vecino" (beggar-thy-neighbour policies).

\section{Transferencias fiscales intergubernamentales}

En un sistema federal, las transferencias federales-provinciales sirven para alcanzar importantes objetivos: aliviar la falta de equilibrio estructural, corregir las ineficiencias y desigualdades fiscales, asegurar la unión económica fijando estándares nacionales mínimos y la igualación fiscal, proporcionando compensaciones para las pérdidas de beneficios y alcanzando la estabilización y la armonización fiscal. La consideración crítica más importante que cabe hacer es que la concesión del diseño debe ser acorde con los fines de la concesión (ver Shah, 1994, 1998).

En los países industrializados, dominan dos tipos de transferencias: las transferencias condicionales para alcanzar estándares nacionales y la igualación de las transferencias para hacer frente a la igualdad regional. En los países desarrollados, con un puñado de excepciones, las transferencias condicionales son de la variedad Pork-Barrel $(P B)$ y no se practica la igualación de las transferencias con un estándar explícito de igualación. En cambio, se utilizan las transferencias de tipo PassingThe-Buck (PTB) en la forma de cuotas de impuesto por impuesto y cuotas de ingresos del Estado con múltiples factores y las concesiones de tipo Asking-for-More-Trouble (AMT) que financiam déficit. Sin unos impuestos limitados o sin descentralización tributaria, en el mundo desarrollado, los tipos de transferencias $P T B$ y AMT financian la mayoría de los gastos subnacionales. En ese proceso, construyen dependencias en las transferencias y desalientan el desarrollo de una gobernabilidad (governance) receptiva y responsable (ver Shah, 1997). En general, estas transferencias crean incentivos para que los gobiernos subnacionales adopten decisiones que sean contrarias a sus intereses económicos a largo plazo en ausencia de tales transferencias. De esta forma, impiden el ajuste natural de las respuestas que conduce a un círculo vicioso de perpetua deprivación de las regiones menos desarrolladas (ver también Courchene, 1996, y Shah, 1996, para una mayor discusión).

Transferencias propiamente estructuradas pueden realzar la competencia para el abastecimiento de servicios públicos, la responsabilidad del sistema fiscal y la coordinación fiscal, a la vez que la cuota general de ingresos del Estado tiene el potencial de debilitarla. En particular, el papel de las transferencias fiscales a la hora de realzar la 
competencia para el abastecimiento de bienes públicos no debe pasarse por alto. Por ejemplo, las transferencias básicas sanitarias y de educación primaria podrían estar disponibles tanto para el sector público como para el sector privado sin ánimo de lucro con la misma base, utilizando, como criterios, la demografía de la población utilizada, la edad escolar de la población, el número de estudiantes matriculados etc. Esto promovería la competencia y la innovación, ya que tanto las instituciones públicas como privadas competirían por fondos públicos. Chile permite que los colegios católicos accedan a la financiación de la educación pública. Las provincias canadienses permiten a los residentes individuales elegir entre colegios públicos y privados para la obtención de sus dólares del impuesto sobre la propiedad. Tal opción ha introducido fuertes incentivos para que los colegios públicos y privados mejoren sus actuaciones y sean competitivos. Tales opciones de financiación resultan especialmente atractivas para proporcionar mayor acceso a los servicios públicos en áreas rurales.

\section{Igualdad regional fiscal}

La desigualdad regional es un área de preocupación para los sistemas fiscales descentralizados y la mayoría de tales sistemas tratan de hacerle frente a través de los poderes de gasto del gobierno nacional o a través de programas solidarios. Federaciones maduras tales como Australia, Canadá y Alemania tienen programas de igualación formal. Este rasgo importante de la descentralización no ha recibido adecuada atención en el diseño de las instituciones en los países en desarrollo. Pese a los serios desequilibrios horizontales fiscales en gran número de los países en desarrollo, no se han intentado programas explícitos de igualación, aunque los objetivos de igualación se han tratado de alcanzar implícitamente en los mecanismos generales de participación en los ingresos usados en Brasil, Colombia, India, Méjico, Nigeria y Pakistán. Estos mecanismos combinan típicamente diversos objetivos y en conflicto en la misma fórmula y resultan cortos respecto a los objetivos individuales. Debido a que estas fórmulas carecen de estándares explícitos de igualación, no consiguen hacer frente de forma satisfactoria a los objetivos de equidad regional.

c) Asegurando la disciplina fiscal bajo el federalismo de valerse por sí mismo

El aseguramiento de la disciplina fiscal representa un importante reto para los países desarrollados. Debido a la presencia de múltiples agentes, un sistema federal impone específicas demandas para asegurar que todos los protagonistas siguen las reglas del juego. En este contexto, el sistema subyacente debe asegurar que los gobiernos en todos los niveles se ven obligados a afrontar las consecuencias financieras de sus decisiones. Esto se lleva a cabo, estableciendo un banco central independiente con el único mandato de lograr la estabilidad en los precios. Es bastante probable que un 
banco central independiente, con el único mandato de lograr la estabilidad en los precios, traiga disciplina al gasto público manteniendo la línea de avances del banco central respecto de los gobiernos y asegurando la integridad e independencia de los mercados financieros. La última de éstas requiere que no se permita a los gobiernos tener instituciones financieras propias o acceso preferente a estas instituciones.

La política fiscal de coordinación también representa un reto importante. En este contexto, las directrices de Maastricht sobre el déficit y la deuda o las normas fiscales impuestas en Brasil proporcionan sistemas útiles, pero no necesariamente una solución a este reto. La experiencia de los países industrializados refleja que los controles y restricciones impuestos federalmente típicamente no funcionan. En cambio, las normas societarias basadas en el conservadurismo fiscal tales como los referenda en Suiza y el activismo político del electorado juegan papeles muy importantes. En último término, los mercados de capital y las agencias de calificación de bonos otorgan una disciplina más efectiva a la política fiscal. En este contexto es importante no bloquear la deuda estatal local y no permitir la propiedad de los bancos por parte de ningún nivel del gobierno. La reducida confianza en las cuotas de ingresos del Estado y el aumento de la confianza en ingresos y en bloques de transferencias condicionales, determinaría una mayor responsabilidad. La descentralización tributaria también resulta importante para establecer una confianza en el sector privado para que preste a los gobiernos locales y comparta los riesgos y los beneficios de prestar. La transparencia en el proceso presupuestario y en sus instituciones, la responsabilidad hacia el electorado y la disponibilidad general de datos comparativos animan a la disciplina fiscal. Finalmente, un consenso societario de los papeles y los límites de los gobiernos y los repasos periódicos de estos papeles es esencial para controlar los comportamientos desviados de los gobiernos.

d) Cultura burocrática y política e incentivos

En algunos países en desarrollo, la cultura política y burocrática sigue centrada en la dirección y el control manifestando poca preocupación y casi ninguna responsabilidad por la provisión de los servicios públicos. Estableciendo cartas de derechos de ciudadanos e introduciendo una orientación a través de un nuevo contractualismo y gerencialismo, tal y como se discutirá en gran medida en una siguiente sección, puede ser de alguna ayuda.

\section{Descentralización - muy bien la teoría, pero, ¿cuál es la práctica?}

Algunos autores han advertido acerca de un posible cambio en la división de poderes en favor de los gobiernos subnacionales en el ambiente de un país en desarrollo y han resaltado los "peligros de la descentralización" 
(Prud'Homme, 1995; ver también Tanzi, 1996). Estos autores han expresado preocupaciones que van desde el macro de-gerencialismo, la corrupción, el exceso de burocracia, el ensanchamiento de la distancia entre las personas y regiones ricas y pobres bajo un sistema fiscal descentralizado. Estas preocupaciones han sido analizadas por Shah (1998) y Hunier y Shah (1998), entre otros, y se ha descubierto que tienen débiles bases empíricas, ya que el resultado de sistemas descentralizados en todas estas cuestiones es mejor que el de los sistemas fiscales centralizados. La Tabla 1 de Hunier y Shah (1998) muestra un alto grado de asociación positiva entre los índices de la calidad de la gobernabilidad (governance) y el grado de descentralización fiscal. Es aún más sorprendente destacar que alrededor del 35\% de la varianza en la calidad de la gobernabilidad (governance) se explica casi exclusivamente por la descentralización fiscal.

Tabla 1: Correlación del índice de descentralización com los indicadores de calidad de la gobernabilidad (Tamaño de la muestra: 80 países)

\begin{tabular}{|lc|}
\hline & $\begin{array}{c}\text { Coeficiente de } \\
\text { correlación } \\
\text { de Pearson }\end{array}$ \\
\hline Participación ciudadana & \\
Libertad política & $0,599^{* *}$ \\
Estabilidad política & $0,604^{* *}$ \\
Orientación del gobierno & \\
Eficienciajudicial & $0,544^{* *}$ \\
Eficiencia burocrática & $0,540^{* *}$ \\
Ausencia de corrupción & $0,532^{* *}$ \\
Desarrollo social & \\
Índice de desarrollo humano & $0,369^{*}$ \\
Igualdad en los ingresos & $0,373^{*}$ \\
Distribución (inversión del coeficiente Gini) & \\
Gestión económica & \\
Independencia del Banco Central & $0,327^{*}$ \\
Disciplina de gestión de la deuda & 0,263 \\
(Inversión de la deuda al porcentaje PIB) & \\
Apertura de la economía (orientación externa) & $0,523^{* *}$ \\
Índice de calidad de la gobernabilidad & $0,617^{* *}$ \\
\hline
\end{tabular}

* Significante hasta el nivel del 0,05\% (2 tail test).

** Significante hasta el nivel del 0,01 (2 tail test).

Fuente: Huther y Shah (1998). 


\section{Subiéndose al gigante para \\ agacharse: aproximaciones al cambio en la cultura burocrática}

\section{Una cartilla de los resultados orientados a la gestión y evaluación ( $R O M E)$}

El sector público sigue enfrentándose a una crisis de confianza del público tanto en países industrializados como no industrializados. En la mayoría de los países abundan ejemplos de la ineficiencia del gobierno y de su tendencia a la producción de residuos. Por ejemplo, en Estados Unidos, la Administración Federal de Aviación todavía depende de ordenadores prehistóricos con pantallas verdes que funcionan por medio de tubos de aspiradora. Se estima que estos ordenadores imponen el gasto de tres billones de dólares en gasolina para aviones desechados, retrasos, conexiones entre vuelos perdidos y costes de empleo. El Departamento de Defensa de Estados Unidos (Pentágono) ha pagado en el pasado 89 dólares por destornilladores de un dólar y el Departamento de Agricultura de US hasta hace poco tenía 2.700 palabras para especificar el término "patatas fritas". Por supuesto, estos ejemplos palidecen en comparación con los grandes robos llevados a cabo en países desarrollados por "errantes bandidos políticos y burocráticos". En países desarrollados, los ciudadanos esperan que los gobiernos hagan más con menos. Por otro lado, en los países en desarrollo importantes disfuncionalidades en la gobernabilidad (governance) pública siguen constituyendo una de las principales preocupaciones. En estos países el gobierno se contempla bien como predador o como criminal. En algunos países el concepto de ciudadanía y de responsabilidad cívica no existen y la efectiva gestión del Estado en este contexto supone que la élite gobernante distribuye los beneficios a sus redes de clientes personalizados. La percepción de algunos gobiernos como "los más fríos de todos los monstruos" - diga lo que diga miente — y todo lo que tiene lo ha robado, y otros que sólo existen para detraer rentas, pueden no estar tan lejos de la verdad.

Una principal dificultad en el caso de estos países es que el robo público llevado a cabo por "bandidos errantes" alienta la subida del capital y del empleo cualificado que conduce a la economía a un estado de colapso, de tal forma que no queda más remedio para sus "bandidos errantes" o para sus súbditos que pedir ayuda externa. Pero tal ayuda externa agrava las tentaciones de tal bandido, ya que él o ella tiene un horizonte a corto plazo. Ayuda, que ese bandido haga de ese país su casa y se convierta en un bandido estacionario, ya que, en tales circunstancias, el horizonte temporal del gobernante se expande y su fortuna se une a la fortuna de la 
nación. Esto explica por qué en muchos países gobernados por "bandidos errantes" la gente muestra una gran tolerancia hacia el cuerpo militar del Estado. Tal transformación conduce típicamente a un breve período de tranquilidad, pero a una escasa mejora de la calidad de vida a largo plazo. El índice de países industrializados indica que la participación democrática es la única forma de gobierno con un índice consistente a la hora de asegurar la buena gobernabilidad. Esto también se debe a que sólo la forma democrática de gobierno asegura los derechos de propiedad y la ejecución de los contratos. Sin embargo, la gobernabilidad democrática no puede simplemente ser dirigida desde arriba. Putnam (1993: 172), en Making Democracy Work, argumenta que (las instituciones democráticas no pueden construirse de arriba abajo. Deben construirse sobre la base de las tradiciones cotidianas de confianza y virtud cívica entre sus ciudadanos". La localización y la responsabilidad de los resultados ayuda a construir tal confianza y virtud.

A lo largo de los años, los países industrializados han mostrado un increíble cambio en la actuación de sus sectores públicos. Es interesante señalar que este cambio fue producido, no a través de un sistema de controles jeraquizados tal y como es el enfoque en la mayoría de los países industrializados, sino más bien, fortaleciendo la responsabilidad de los ciudadanos en general. Los representantes electos establecieron un compromiso siguiendo las líneas del juramento requerido a los miembros de la ciudad de Atenas, que establecía que:

"Lucharemos más y más para acelerar el sentido público de deber público; que de esa forma ... transmitiremos esta ciudad

No sólo no peor, sino mejor, mayor, y con más belleza

Que con la que nos fue transmitida a nosotros."

Esta responsabilidad por los resultados fue fortalecida más aún por la responsabilidad del ejecutivo frente al poder legislativo. Por encima de todo, el énfasis de estos sistemas ha estado en provocar un cambio en la cultura burocrática y en el aspecto de los incentivos a los empleados públicos. Este cambio cultural que se dio durante los años 90 se produjo fortaleciendo los resultados orientados al sector público. Esto se llevó a cabo distrayendo la atención de los procesos burocráticos internos y de los input controls (controles fuertes), a la responsabilidad por los resultados (controles débiles). Mientras que diversos países han seguido políticas diversas para alcanzar esta transformación, la estructura subyacente que dirige estas reformas está uniforme y firmemente fundada en una estructura de gestión y evaluación orientada a los resultados (ROME). Bajo la estructura $R O M E$, una cadena basada en los resultados proporciona un patrón para medir la actuación del sector público. El concentrar la 
cuestión en el diálogo gerencial refuerza la propiedad y responsabilidad conjunta del principal y el agente a la hora de alcanzar metas compartidas, resaltando los términos de la confianza mutua.

\section{Cadena de gestión y evaluación orientados a la obtención de resultados}

Programa/proyecto $\rightarrow$ inputs $\rightarrow$ actividades $\rightarrow$ outputs $\rightarrow$ alcance $\rightarrow$ resultado (propósito) $\rightarrow$ impacto (meta).

Casi todas las aproximaciones de tipo ROME tienen los siguientes elementos comunes:

- Acuerdos de programas de trabajo y contratos basados en outputs preespecificados, objetivos de actuación y asignaciones presupuestarias.

- Flexibilidad gerencial para la responsabilidad por resultados.

- Principio subsidiario.

- Incentivos para el coste de eficiencia.

La gestión y evaluación orientada a la obtención de resultados $(R O M E)$ proporciona una estructura coherente para la planificación estratégica y para la gestión basada en el apredizaje y la responsabilidad en un ambiente descentralizado. La clave para una ejecución satisfactoria de la estructura $R O M E$ se consigue a través de la transparencia que se alcanza mediante el compromiso público a unos pocos pero vitales resultados esperados, en especial, outputs que conduzcan a resultados. Más aún, estos resultados se establecen en términos de logros de desarrollo. De esta forma, programas, actividades, procesos y recursos se alinean con las metas estratégicas de la agencia y la flexibilidad en la definición de proyectos y la implementación se consigue a través del cambio del énfasis, lo cual, a su vez, se lleva a cabo mediante una medición estricta de los inputs para los resultados de su actuación y sus medidas. El seguimiento del proceso hacia resultados esperados se lleva a cabo a través de indicadores, que se negocian entre el proveedor y la agencia financiadora. Esta meta conjunta de establecer e informar ayuda a asegurar la satisfacción de los clientes de forma continuada, a la vez que crea asociaciones y propiedad dentro del proyecto.

Las reformas del ROME en el marco de una institución se ven mantenidas por el traspaso y la delegación de autoridad. Esto requiere un flujo de información en dos sentidos, que se alcanza a través de un mecanismo fortalecido de responsabilidad, en la forma de informar sobre la actuación, mayor énfasis en la medición y evaluación de resultados, y acuerdos de actuación individual que se centran en los resultados. De esta forma, bajo el sistema $R O M E$, la responsabilidad se convierte en positiva y mira hacia adelante, basada en continuas y sistemáticas retroacciones y aprendizaje. Esto quiere decir que cada unidad proporciona información 
sobre los resultados alcanzados en contra de los fines estratégicos de la agencia, permitiendo así puntos de referencia para comparaciones y para aprendizaje a lo largo de las fronteras organizacionales. Además, también proporciona una gestión superior con pruebas concretas en las que basar su asignación de decisiones. Así, el traspaso, la participación y la responsabilidad también son aspectos importantes en este proceso (ver Banco Mundial, 1999).

Bajo el sistema ROME las asignaciones presupuestarias apoyan los acuerdos sobre programas de trabajo y contratos basados en outputs preespecificados y objetivos de comportamiento. La flexibilidad gerencial en las selección de inputs incluyendo la contratación y el despido de personal y el programa de ejecución, son plenamente respetados a la vez que son considerados responsables de obtener resultados. El principio subsidiario de menor nivel en la asignación de responsabilidad, a menos que se pueda establecer un caso para una asignación de mayor nivel, fortalece la responsabilidad por los resultados a la vez que realza la consistencia de la previsión de servicio público con preferencias locales. Por último, bajo la estructura de ROME, el coste de la eficiencia se agradece a través de la retención de los ahorros. Para el cálculo de los costes se requiere el uso del coste basado en la actividad incluyendo las comisiones de capital/partidas del activo. En la medida en que la cuestión central de la aproximación es el aprendizaje, puede tolerarse la imposibilidad de alcanzar los compromisos, pero el fallo en compartir los valores puede conducir a la imposición de graves sanciones.

\section{Las implicaciones de $R O M E$ para la reforma del funcionariado}

En los países desarrollados a los funcionarios típicamente se les paga poco por el trabajo realizado, pero, en cambio, los altos perks y otros se enriquecen traficando con los puestos públicos y mediante la corrupción. Tienen propiedades vitalicias. No se tolera la innovación y la asunción de riesgos. En un intento de limitar el tráfico con puestos públicos, se ejecutan fuertes controles de input y responsabilidad de arriba abajo. Además, los funcionarios veteranos rotan periódicamente de una posición a otra. Pero tales prácticas debilitan aún más la responsabilidad. En contraste con éste, una estructura ROME atrae hacia sí salarios competitivos y la especialización de tareas (cultura-de-quedarse-con-ello) y la carencia de propiedades formales. A los proveedores públicos se les da libertad para fallar o triunfar. En cambio, los empleados públicos mantienen tanto tiempo sus trabajos que son capaces de cumplir los términos de los contratos. Las persistentes derrotas inician el proceso de salida. La habilidad de responder frente a la ciudadanía y la responsabilidad por los 
resultados son la base de esta aproximación. La estructura $R O M E$ ofrece un mayor potencial en los países desarrollados para que mejoren la gobernabilidad (governance) del sector público alimentando a una gobernabilidad receptiva y responsable. Puede que también resulte ser una de las armas más potentes contra la corrupción burocrática y la fechoría. Un estudio empírico reciente acerca de los factores determinantes de la corrupción por Gurgur y Shah (1999) apoya este punto de vista, al mostrar que la cultura política y burocrática y la centralización de la autoridad representan el factor más determinante de la corrupción en la muestra de 30 países. Llegan más allá para concluir que no es probable que subir el pago y los salarios del sector público como parte de la estrategia anticorrupción lleve a ningún tipo de mejoras en la reducción de la corrupción.

\section{Tabla 1: Haciendo que el perro mueva su cola}

\begin{tabular}{|l|l|}
\hline Actual & Futura \\
\hline Controles input. & Cuestiones de resultado. \\
Responsabilidad de arriba abajo. & Responsabilidad de abajo arriba. \\
Bajos salarios pero alto perkes. & Salarios competitivos pero poco más. \\
Nombramientos de por vida y & Cultura de quedarse con ello, \\
rotaciones. & pero salidas com fallos persistentes. \\
Intolerancia hacia el riesgo/acertar. & Libertad para fallar o acertar. \\
\hline
\end{tabular}

\section{Experiencia con el sistema $R O M E$}

Varios países han experimentado con varias versiones de ROME. De éstos, las experiencias de Nueva Zelanda, Canadá y Malasia ofrecen información interesante tal y como se indica más adelante:

\section{El Estado sujeto a contrato: el modelo neozelandés}

Nueva Zelanda representa una de las experiencias más evidentes en la transformación del sector público utilizando una aproximación a cuestiones esenciales de las funciones del gobierno, a través de una gestión y una medición de un sector privado. Para introducir un cambio cultural de controles input a responsabilidad output en el sector público, durante la última década, Nueva Zelanda descartó un sistema funcionarial basado en la propiedad y, en cambio, hizo que todas las posiciones públicas tuvieran una base contractual basada en una serie de resultados acordados. Se requirió incluso al gobernador del banco central a que celebrara un contrato con el Parlamento. Según los términos de este contrato, la propiedad del gobernador del banco central estaba unida a una inflación que se mantuviera 
en la banda del 3\% anual. El desarrollo de políticas y la implementación de funciones, la financiación, la compra y la provisión de funciones estaban separadas. Esto permitió al gobierno concentrarse en la política y en la financiación y asociar al sector privado con el sector público en la función prevista. La gestión del programa se descentralizó en el momento de la entrega y a los gerentes se les dio la flexibilidad y la autonomía en la asignación presupuestaria y en la implementación del programa dentro de la estructura política y del presupuesto definido. Se introdujeron el recargo de capital y el aumento de la contabilidad para tener así una visión general de la fuente del coste de cada una de las actividades del sector público. Las funciones no públicas bien se comercializaron o se privatizaron. Se alentó la gestión fiscal responsable a través del requerimiento de que se mantuviera una red positiva válida para el gobierno como parte del contrato por parte del Ministro de Finanzas.

La nueva versión contractualista del ROME introducida en Nueva Zelanda llevó a una transformación importante de la economía Kiwi. Se transformó de una economía muy protegida y regulada con una expansiva gama de intervenciones intrusivas y de gasto, a una economía abierta y desregulada con un sector público ágil y eficiente (ver Walker, 1996). Se eliminaron los déficit del gobierno central, se redujo la deuda y la red de valor (net worth) del gobierno se volvió positiva a la vez que se mejoro la calidad y la cantidad de los servicios públicos. Se alcanzaron resultados incluso más impresionantes a nivel local. Por ejemplo, el Alcalde de Papakura, al introducir el nuevo contractualismo, provocó un cambio increíble en las fortunas del pueblo de Papakura al eliminar la deuda, reducir los impuestos, a la vez que mejoraba la calidad y la cantidad de las previsiones del servicio público.

Con toda certeza hubo limitados fallos en la política social con esta aproximación. La previsión de servicio social para las comunidades de minorías experimentó algunas dificultades debido a que, bajo la comercialización, los recortes por presiones del coste llevaron de forma ocasional a un acceso restringido por parte de las comunidades de minorías. En casos aislados, el nuevo contractualismo falló debido a que la incompetencia burocrática no consiguió asegurar estándares estrictos de seguridad, tal y como se presenciaron en el colapso de una plataforma visual recientemente construida en "Cave Creek" que ocasionó la muerte de amplio número de turistas.

\section{Haciendo que el gobierno vaya bien. La aproximación canadiense}

Canadá adoptó en 1994 su propia versión de $R O M E$ para hacer frente a los persistentes déficit del sector público, a una amplia deuda y a la creciente insatisfacción de los ciudadanos con el sector público. Canadá rechazó el nuevo contractualismo y en cambio optó por la así llamada 
estructura del servicio de entrega alternativo (ASD) para las reformas del sector público utilizando la llamada nueva aproximación gerencialista. El ASD representa un "proceso de reestructuración del sector público que mejora los servicios de entrega a los ciudadanos compartiendo las funciones de gobernabilidad (governance) con los individuos, los grupos de comunidades, el sector privado y otras entidades de gobierno". Este proceso se caracteriza por ser un proceso consultivo y participativo.

Como parte del programa de revisión bajo el ASD, se requirió a los departamentos y agencias que revisaran sus actividades y programas frente a las siguientes directrices:

Seis Directrices del Programa de Revisión

1. Test del interés público. — ¿Sigue el área del programa o la actividad sirviendo al interés público?

2. Test del papel del gobierno. - ¿Existe un papel legitimado y necesario para el gobierno en esa área del programa o actividad?

3. Test del federalismo. - ¿Es el papel actual del gobierno federal adecuado, o es el programa un candidato para el realineamiento con la provincia?

4. Test de la asociación.—¿Qué actividades o programas deberían o podrían ser transferidos en su conjunto o en parte al sector privado/ voluntario?

5. Test de la eficiencia.- ¿ $\mathrm{Si}$ el programa o las actividades continúan, cómo podría mejorarse su eficacia?

6. Test acerca de la posibilidad de permitírselo. — ¿Es el paquete resultante de programas y actividades uno permitido dentro de las restricciones fiscales? Si no lo es, ¿qué programas o actividades serían abandonados?

La experiencia canadiense con ASD ha mostrado resultados sorprendentes hasta la fecha. El déficit federal se redujo del 7,5\% del GDP en 1993 a un presupuesto equilibrado en 1998. El número de departamentos federales se redujo de 38 a 25 y el tamaño del funcionariado se redujo de $220 \mathrm{~K}$ a $178 \mathrm{~K}$. Las asignaciones presupuestarias de servicios sociales, justicia, ciencia y tecnología se aumentaron, mientras que los servicios restantes se redujeron en las asignaciones presupuestarias. El realzamiento de servicios de entrega centrados en los ciudadanos se alcanzó a través de la agrupación de los servicios en torno a las necesidades de los ciudadanos, la reforma reguladora para alentar la competencia y la innovación, la recuperación del coste de servicios que benefician a segmentos determinados, y la continua reevaluación de los programas para el apoyo de mecanismos de servicios de entrega alternativos. El impacto global de estas reformas fue una mejora del servicio de entrega y de la satisfacción ciudadana. 


\section{De gobierno a gobernabilidad en Malasia}

ROME no se construyó en un día y, tal y como se discutió anteriormente, no existe literatura abundante en cuanto a los tipos de innovaciones que se introdujeron de forma pionera en Nueva Zelanda, Australia y Canadá, entre otros. Con suficiente interés, esta literatura no ha reconocido completamente la contribución de Malasia donde algunas de las innovaciones preceden la experiencia de los países industrializados. La experiencia de Malasia es de especial relevancia para los países desarrollados, ya que el sector público de Malasia sufrió al menos algunas de las disfuncionalidades que se han sufrido en otros países en desarrollo a finales de $\operatorname{los} 80$. Gracias a unas iniciativas valerosas llevadas a cabo por Ahmad Sarji, bajo el liderazgo del Primer Ministro Mahatir Mohammed, Malasia tuvo un nivel significante de éxito a la hora de conseguir que el gigante sector público se arrodillara para que los ciudadanos pudieran subirse a bordo.

Desde principios de los noventa, Malasia había, de forma gradual, puesto en su lugar aspectos de la gestión orientada a la obtención de resultados para crear una estructura de gobernabilidad del sector público receptiva y responsable. Varios de los elementos de esta aproximación que se han implementado son:

- Misiones y valores: a todas las agencias públicas se les requiere que especifiquen su misión y valores con la intención de justificar sus papeles y para inculcar valores positivos en la Administración pública.

- Fortalecimiento de la orientación al cliente: se estableció una carta de derechos para el cliente en 1993. Ésta requiere que todas las agencias identifiquen a sus consumidores y establezcan cuáles son sus necesidades. A las agencias se les requiere además que notifiquen a los clientes los estándares de servicios disponibles. Se espera que las agencias públicas informen anualmente tanto de la mejora de los servicios como de los fallos en el acatamiento. Los clientes tienen derecho a una indemnización o compensación por medio de la Oficina de Quejas Públicas.

- Responsabilidad gerencial y responsabilidad reforzada por los resultados: esto se consigue a través de la implementación de un output basado en un sistema presupuestario y un sistema de contabilidad basado en la actividad. Además, ha introducido recargos de capital y un aumento de la contabilidad. El sistema presupuestario del output requiere "acuerdos sobre programas" para la entrega de outputs, pero permite flexibilidad gerencial a la hora de alcanzar los resultados acordados. Los indicadores de la actuación para las agencias del gobierno y otros proveedores del sector público se mantienen.

- Toma de decisiones descentralizada: Malasia a lo largo del tiempo ha tratado de fortalecer la toma de decisiones descentralizada 
fortaleciendo los gobiernos locales y desconcentrando las funciones del gobierno federal.

- Fortaleciendo la integridad del funcionariado de Malasia: Malasia dispone de una de las leyes anticorrupción más severas y dedica importantes recursos a implementar esta ley.

- Aproximación asociada a la entrega de servicios: se ha tratado de alcanzar una aproximación de asociación al servicio de entrega se ha tratado de alcanzar mediante el aseguramiento del consejo político, la desregulación y la promoción activa de la colaboración pública-privada en los servicios públicos.

- Asegurando la integridad financiera: esto se alcanza por medio de una auditoría interna y externa. El Auditor general proporciona al Parlamento una auditoría de su integridad financiera. Este informe es ampliamente difundido.

En suma, Malasia está dentro de lo más novedoso en cuanto al desarrollo institucional del sector público, la innovación y la actuación en los países desarrollados. Ha seguido aproximaciones innovadoras para la mejora de la actuación del sector público. Su reto es fortalecer la nueva cultura de gobernabilidad que ha tratado de crear enfrentándose con la implementación que requiere un profundo aprendizaje y una acción correctiva. Además, necesita comenzar a hacer frente a determinados aspectos que hasta ahora han recibido una atención inadecuada. Éstos incluyen (a) fortalecer la independencia del banco central y centrar su papel únicamente en la estabilidad de los precios, y (b) alcanzar una mejor integración de los procesos de desarrollo y presupuesto operantes.

\section{Mas allá de ROME. Midiendo la actuación cuando no hay una conclusión}

Toda la actuación del gobierno controlado resulta de interés para conseguir una medida general de la actuación del sector público y de la responsabilidad ciudadana del régimen político. Tal tipo de medida es cada vez más popular en los países industrializados. El Estado de Oregón, USA, estableció una oficina independiente para desarrollar y controlar las medidas del bienestar social de los ciudadanos del Estado (158 medidas de ese tipo en 1991, ahora reducidas a 20 en 1999). El Estado de Florida estableció inicialmente 268 indicadores que se encargaban del progreso de las familias y comunidades, la seguridad, el aprendizaje, la salud, la economía, el medio ambiente y el gobierno. Más recientemente se ha abandonado ese esfuerzo. La provincia de Alberta, Canadá, ha establecido 27 indicadores que miden la calidad de vida. Nueva Zelanda informa acerca de la estructura del gobierno. Las Naciones Unidas publican indicadores del desarrollo humano y Hullier y Shah (1998) desarrollaron indicadores 
comprensivos de la calidad de la gobernabilidad (governance), incorporando la participación ciudadana, la orientación gubernamental, el desarrollo social y la gestión económica para una muestra de 80 países.

La experiencia con todas las medidas del comportamiento global del gobierno ha dado resultados variados. Esto se debe a que los medios de comunicación son escépticos acerca de la exactitud de las estadísticas, y en los sistemas políticos con separación entre el poder legislativo y el poder ejecutivo, las legislaturas están preocupadas ante el potencial abuso de este instrumento para minar la autoridad legislativa. En general, ante la ausencia de una crisis fundamental, las políticas de toma de decisiones de carácter presupuestario reducen la utilidad de estos indicadores de actuación. Una mayor dificultad aún respecto de los indicadores agregados de actuación surge de "buscar claves bajo la lámpara post refleja", que significa que aquello que es medible y que se mide puede no ser relevante para la política o para el objetivo de responsabilidad. A nivel conceptual, las medidas de resultado ofrecen una responsabilidad difusa. En cambio, el centrarse en outputs y en su alcance, tal y como se ha practicado en Nueva Zelanda y Malasia, ofrece mayores potenciales de responsabilidad por los resultados.

\section{Epílogo - ROME. ¿Acaso un mapa de carreteras que conduce a desastres $y$ ruinas, o a un futuro mejor?}

El éxito de la puesta en práctica de $R O M E$ en unos pocos países seleccionados ha provocado una acalorada controversia y debate entre los prácticos de la gestión del sector público con un grupo vocal (Schick, 1999, es el mayor exponente en este punto de vista), argumentando en contra de la aplicación de tales principios en los países desarrollados. Una plétora de argumentos se ponen de manifiesto para defender este punto de vista. Se ha defendido que el verdadero problema de la reforma del funcionariado no es su eficiencia, sino su bajo desarrollo. Los sistemas de control input no están bien desarrollados. No hay ningún sentido de la responsabilidad pública y, como consecuencia de esto, la discrecionalidad gerencial alienta las posibilidades de abuso del cargo público para obtener ganancias de carácter privado. Debido a la interferencia política, es débil el potencial para la ejecución de contratos. El uso de $R O M E$ debilitará aún más la responsabilidad de arriba abajo como centro de los cambios de resultados más que de inputs, reglas y procedimientos. Se va incluso más allá en la argumentación al decir que la utilización de esta aproximación no servirá para el arte (investigación y desarrollo) y la copia (ej., disaster relief) de organizaciones como centro de los outputs desalentará la innovación, y pondrá en riesgo la toma de decisiones y el largo plazo de responsabilidad. En los servicios sociales, se argumenta que el acceso a 
los necesitados y a los pobres puede no asegurarse bajo un sistema que pone gran interés en la eficiencia operacional. Por último, otros han argumentado que el $R O M E$ es una moda y que los países desarrollados deberán esperar simplemente a que se pase de moda y surja una nueva moda.

Aunque los argumentos expuestos en contra del uso de $R O M E$ tienen algún mérito, en comparación, el caso para la aplicación del $R O M E$ en países desarrollados se ha fortalecido aún más a la vista de la debilidad de las instituciones, cuestión que se resaltó algo más arriba. El argumento de la burocracia subdesarrollada y de los controles de input sugiere que los sistemas modernos de contabilidad que encuentran el flujo de inputs no han resultado ser de ayuda. Esto se debe a que la experiencia demuestra que las mejoras en el comportamiento derivadas de la implementación de tales sistemas han sido mínimas y, en cambio, estos sistemas sirven para cubrir el abuso de fondos públicos ayudando a "poner los libros en orden". En la medida en que los outputs para una gran mayoría de servicios públicos se observan fácilmente y se puede medir su alcance, $R O M E$ proporciona un mejor control de la responsabilidad en la gobernabilidad en ambientes institucionales débiles. La responsabilidad basada en un input jerárquico no ha conseguido típicamente llevar a cabo los mandatos del sector público. Sin duda, las organizaciones de habilidades y copiado requieren cuidado en cuanto a cómo se ha de evaluar su cadena basada en los resultados. En los servicios sociales, es esencial un diseño similar de incentivos para prevenir los fallos y, en cambio, lo que se hace es alentar el acceso de todos por medio de la competencia y la innovación. Una estructura de concesión que trata todos los abastecimientos públicos y privados, sobre la misma base con la continuidad de la elegibilidad, unida a las condiciones en la accesibilidad de los servicios, y el acceso a tales servicios más que los niveles de gasto, puede hacer frente al peligro moral (ver Tabla 2). ROME tampoco es por supuesto una moda, ya que se puso en práctica con gran éxito en las sociedades tradicionales mucho antes de que la burocracia moderna se inventara. Incluso en la toma de decisiones personal y familiar, ROME es una aproximación llevada a cabo normalmente por la mayoría de los individuos en la toma de decisiones, por ejemplo, construir y arreglar una casa y la búsqueda de otros servicios. Muchos países desarrollados que tienen que enfrentarse a amplias crisis fiscales, si no existiera ayuda externa simplemente no tendrían más remedio que adoptar ROME para superar esas crisis para poner su casa en orden. En general, la responsabilidad de abajo arriba es la clave del éxito de $R O M E$ y tal responsabilidad requiere la toma de decisiones descentralizada. En conclusión, la globalización, la localización y $R O M E$ ofrecen un fuerte potencial para la mejora de la actuación del sector público en países desarrollados. 
Tabla 2: Las concesiones de educación para alentar la competencia y la innovación

Base de asignación entre los gobiernos locales: Población de edades entre 5-17.

Distribución de providers: Igual por alumno tanto para el gobierno como para los colegios privados.

Condiciones: Acceso universal a la educación primaria y secundaria independientemente del sueldo de los padres. Ninguna condición para el uso de fondos concesionales.

Sanciones: Censura pública, reducción de la concesión de fondos.

Incentivos: Retención de los ahorros.

\section{El mega cambio y sus implicaciones}

\section{Realineamientos jurisdiccionales emergentes}

El debate sobre la globalización y la localización y el creciente nivel de insatisfacción con la actuación del sector público está provocando un replanteamiento de las cuestiones de asignación y también un realineamiento jurisdiccional en muchos países a lo largo del globo. La Tabla 3 representa una pespectiva más novedosa del federalismo, relativa a la asignación de responsabilidades teniendo en cuenta las consideraciones hechas arriba. Esta Tabla muestra que funciones tales como la regulación de transacciones financieras, el comercio internacional, el medio ambiente global, la migración internacional, necesitan ser aprobadas arriba (de forma centralizada) más allá de las naciones-Estados. Algunas funciones infranacionales, tales como el adiestramiento, deberán tener mayores entradas del gobierno central (centralización) y las funciones locales deberían ser completamente descentralizadas y deberían implicar una mayor participación de la sociedad civil y del sector privado. En los países desarrollados, el replanteamiento de estos arreglos ha llevado a una descentralización gradual y en porciones de las responsabilidades por los servicios públicos locales a niveles inferiores en un número pequeño pero creciente de países. El desarrollo y el fortalecimiento de los arreglos institucionales para el éxito de las políticas descentralizadas se ha quedado atrás de forma significativa. El fortalecimiento de la capacidad local para adquirir y entregar los servicios locales sólo ha recibido una atención limitada. Incluso el fortalecimiento de las funciones de nivel central e intermedio requerido para el éxito de tal arreglo, no siempre se ha materializado. De hecho, en algunos países, la descentralización viene motivada por el cambio del déficit presupuestario y las cargas asociadas a la deuda 
de los gobiernos infranacionales. La resistencia burocrática a la implementación de las reformas tipo ROME sigue siendo fuerte y, como consecuencia de ello, no se han efectuado mejoras importantes en los países desarrollados.

\section{Tabla 3: Surgimiento de arreglos: globalización, centralización y localización}

Más allá de las naciones-Estado: Regulación de las transacciones financieras, impuestos de sociedades comercio internacional, medio ambiente global, telecomunicaciones, estándares internacionales, migración internacional, vista de las condiciones de gobernabilidad, seguridad global y riesgos de la gestión, producción transnacional, inversion y transferencias en tecnología.

Centralización: Políticas sociales y medio cambientales por medio de acuerdos internacionales, realzamiento de habilidades para la competitividad internacional, redes de seguridad social, vigilância y asistencia técnica a gobiernos infranacionales.

Regionalización/localización/privatización: Todo regional/funciones locales.

\section{La estructura de gobernabilidad emergente en el siglo XXI}

Mientras, los arreglos que tienen hoy en día lugar en el mundo representan diversos rasgos de la supranacionalización, centralización, provincialización y localización. Sin embargo, la visión de la estructura de gobernabilidad que está poco a poco prevaleciendo es una tendente a un cambio de estructuras constitucionales unitarias a constituciones federales o confederales para la mayor parte del país. Implica que es probable que nos movamos de un mundo centralizado a un mundo globalizado y localizado. El papel de los gobiernos centrales en un mundo así cambiaría de una autoridad gerencial a un papel de liderazgo en un ambiente de gobierno con múltiples centros. La cultura de la gobernabilidad también está cambiando poco a poco de un modo de operación burocrático a uno participatorio; de dirección y control, a responsabilidad por resultados; de ser internamente dependiente a ser competitivo e innovador; de ser cerrado y lento a ser abierto y rápido; y de la intolerancia del riesgo a permitir la libertad de fallar o ganar. La crisis financiera a lo largo del mundo está impidiendo este cambio y como consecuencia de ello la nueva visión tardará algún tiempo en tomar forma en el siglo XXI (ver Tabla 4) y en muchos países desarrollados puede, de hecho, no materializarse debido a dificultades conceptuales y prácticas que se mencionan en las siguientes secciones. 
Tabla 4: La estructura de gobernabilidad, el siglo XX versus el siglo XXI

\begin{tabular}{|ll|}
\hline Siglo XX & Siglo XXI \\
\hline Unitário & Federal/Confederal \\
Centralizado & Globalizado y localizado \\
El centro gestiona & El centro dirige \\
Burocrático & Participatorio \\
Responsabilidad de arriba abajo & Responsabilidad de abajo arriba \\
Centrándose en las reglas & Flexibilidad gerencial, pero \\
y procedimiento & responsabilidad por resultados \\
Nombramientos vitalicios del & Contractualismo \\
funcionariado & \\
Dirección y Control & Receptivo y Responsable \\
Internamente dependiente & Competitivo \\
Cerrado y lento & Abierto y rápido \\
Intolerancia de los riesgos & Libertad para fallar o acertar \\
Centrándose en el gobierno & Centrándose en la gobernabilidad \\
\hline
\end{tabular}

\section{Por qué la carretera hacia la reforma permanece como un campo de sueños para los países desarrollados?: consideraciones teóricas}

Una forma sencilla de ver por qué el sector público es disfuncional y provee mucho en los países desarrollados, pero, a pesar de ello, es difícil de reformar, es mirar más de cerca la misión del sector público y sus valores, su ambiente de autoridad y su capacidad operacional.

a) Las misiones y valores de sector público. Los valores y las normas societarias, por ejemplo, tal y como se recogen en la Constitución o en los informes de políticas anuales presupuestarias, pueden ser útiles como puntos de referencia para mandatos del sector público y para los valores inherentes en estos mandatos. También deberían tomarse en consideración aquellas normas no escritas pero de aceptación y reconocimiento general. En los países industrializados, la misión y los valores del sector público se escriben en términos de una estructura política a medio plazo. Por ejemplo, existe una exigencia formal en Nueva Zelanda de que los informes de este tipo se recojan en tablas en el Parlamento para el 31 de marzo (como unos 2 o 3 meses antes que el informe presupuestario). Los valores del sector público apenas se aplican en los países desarrollados. Esto se debe a que el sector público sigue estando orientado hacia "la dirección y el control", en vez de a servir a su ciudadanía. Para un funcionario entrenado en un sistema 
de "dirección y control", la necesidad de desarrollar un código de conducta orientado a la clientela puede parecer frívolo.

b) Un ambiente autorizativo. Esto incluye instituciones formales (procesos presupuestarios e instituciones) e informales de participación y responsabilidad. ¿Actúan estas instituciones y procesos tal y como se pretende que lo hagan a la hora de proporcionar a un gobierno capacitado para que el sector público alcance sus fines? ¿Actúan los diversos niveles del gobierno conforme al espíritu de la Constitución a la hora de ejercitar sus responsabilidades? ¿Cuáles son los límites y contrapesos contra el comportamiento desviado? ¿Se garantiza la independencia del banco central, del poder judicial y del auditor general? ¿El banco central se centrará sólo en la estabilidad de precios, o se espera que persiga múltiples fines? ¿Existen normas formales que aseguren la disciplina fiscal? ¿Es el diseño de transferencias conforme con sus objetivos? ¿Existen agencias privadas que ordenen por niveles los diversos niveles del gobierno por la valía de sus créditos? ¿Los préstamos del sector público están sujetos a la disciplina del mercado financiero? ¿Cómo se mide la actuación del gobierno? ¿Hay alguien que controle los indicadores de salida y resultado para los servicios públicos? En los países industrializados, la gente se adhiere de forma estricta a las normas institucionales y existen graves sanciones morales, legales de votantes y de mercado contra el no cumplimiento. En el ambiente de un país desarrollado, el no cumplimiento a menudo ni se controla ni está sujeto a sanciones.

c) Capacidad operacional y restricciones. Aquello que se autoriza no es necesariamente lo que se lleva a cabo, ya que puede ocurrir que la capacidad operacional que hay disponible no sea consistente con la tarea a mano. Más aún, puede que incluso la capacidad operacional disponible se vea restringida por la cultura burocrática o por los incentivos que premian la dirección y el control, y la corrupción y el mecenazgo. Algunas preguntas claves, cuyas respuestas nos darán un mayor entendimiento de la capacidad operacional incluyen: ¿Tienen las agencias con la responsabilidad de llevar a cabo diversas tareas la capacidad para llevarlas a cabo? ¿Tienen la mezcla de habilidades adecuadas al igual que los incentivos para hacer las cosas que deben hacer y de forma correcta? ¿Es la cultura burocrática consistente con el alcance de los objetivos sociales? ¿Existen contratos vinculantes para gestores públicos respecto de la actuación de output? ¿Ayuda la participación de la sociedad civil a aliviar algunas de estas restricciones? Mientras que, en los países industrializados, se espera que las respuestas a la mayoría de las preguntas expuestas arriba sea afirmativa, esto no resulta ser cierto en el caso de un país desarrollado. 


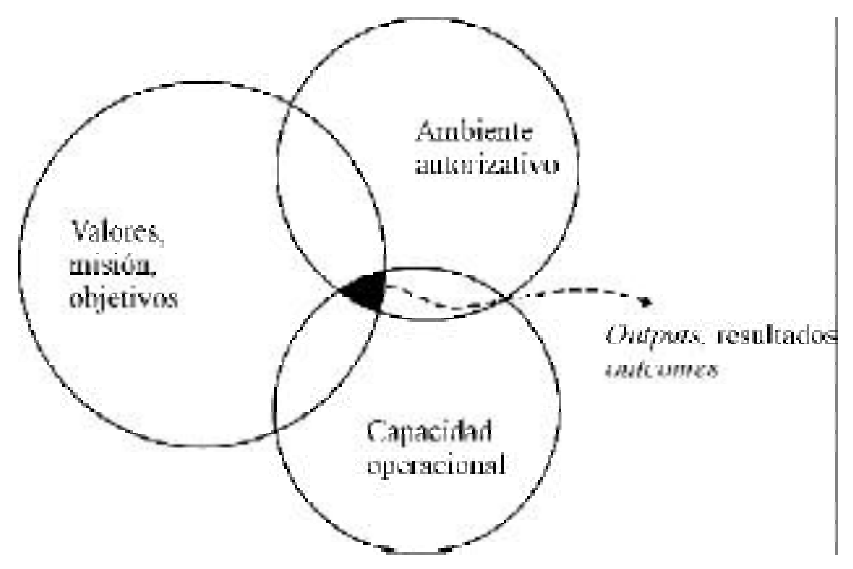

En cualquier país, el reto de la reforma del sector público es armonizar las misiones y los valores, el ambiente autorizativo y la capacidad operacional del sector público de tal forma que haya al menos una correspondencia casi perfecta, sino perfecta, entre estos tres aspectos de la gobernabilidad (governance) (ver la Figura 1). Tal tarea resulta intimidante para muchos países en desarrollo, ya que a menudo tienen metas muy elevadas, pero carecen del ambiente autorizativo capaz de traducir esas metas en una estructura política. Este problema suele complicarse aún más con los incentivos burocráticos que hacen que cualquier capacidad operacional disponible para implementar tal estructura sea completamente disfuncional.

La Tabla 5 representa una comparación estilizada del ambiente institucional en una sociedad primitiva, en un país en desarrollo y en un país industrializado. Es interesante observar que mientras que la capacidad técnica en sentido moderno es inexistente en una sociedad tradicional, debido a la armonización de sus metas, su ambiente autorizativo y su capacidad operacional, los resultados del sector público fueron acordes con las preferencias de sus miembros. Las culturas de tales sociedades muy a menudo se centran en responsabilidades basadas en resultados. El sistema de premios y castigos fue creíble y veloz y muchas de las relaciones de negocios estaban basadas en la informalidad y la confianza. De esta forma mientras que el PIB per capita en tales sociedades era bastante bajo, se observó que la satisfacción de sus miembros y la acción colectiva, el llamado "índice viagara" era bastante alto y posiblemente se encontraba no muy lejos del grado de satisfacción experimentado con el sector público en las sociedades industrializadas de hoy en día.

Esto contrasta claramente con el dibujo que puede realizarse de un país típicamente en desarrollo. En tal país, hay una discordancia en los 
fines de la sociedad, en el ambiente competencial y en la capacidad operacional. Como consecuencia de esta desarmonía, no se consigue realizar mucho, y las expectativas de los ciudadanos se ven truncadas. La falta de responsabilidad y el hecho de que la cultura de evaluación establezca su centro en freír un pez grande de vez en cuando y no hacer nada con el malestar del sistema significa que se ven truncados cualesquiera sistemas de autocorrección que existan. La semi-formalidad impone costes adicionales a la hora de negociar, pero no conduce a ningún tipo de beneficios en las relaciones de negocios debido a la falta de respeto por la ley. Los contratos no se respetan y, por tanto, tienen escaso valor. A la vista de esta naturaleza completamente disfuncional del sector público existente en muchos países en desarrollo, es importante para éstos saltar hacia delante (o incluso hacia atrás) a una cultura del sector público que pone el interés en la orientación de los clientes y en la responsabilidad por resultados. Sin embargo, es poco probable que esto suceda pronto por razones que se discutirán posteriormente.

Tabla 5: Ambiente institucional del Sector Público.

\section{Hechos definidos}

\begin{tabular}{|c|c|c|c|}
\hline Tipos & Tradicional & En desarrollo & Industrial \\
\hline Metas & Claras y realistas & Vagas y grandiosas & Claras y realistas \\
\hline $\begin{array}{c}\text { Ambiente } \\
\text { competencial }\end{array}$ & Fuerte & Débil & Fuerte \\
\hline $\begin{array}{c}\text { Capacidad } \\
\text { operativa }\end{array}$ & $\begin{array}{l}\text { Consistente } \mathrm{y} \\
\text { funcional }\end{array}$ & Disfuncional & $\begin{array}{c}\text { Consistente y } \\
\text { funcional }\end{array}$ \\
\hline $\begin{array}{l}\text { Capacidad } \\
\text { evaluadora }\end{array}$ & Fuerte & Débil & Fuerte \\
\hline $\begin{array}{l}\text { Orientación del } \\
\text { sector público }\end{array}$ & Output & $\begin{array}{c}\text { Inputs, } \\
\text { dirección/control }\end{array}$ & $\begin{array}{c}\text { Monitorización, } \\
\text { inputs, outputs y } \\
\text { outcomes }\end{array}$ \\
\hline $\begin{array}{r}\text { Toma de } \\
\text { decisiones }\end{array}$ & Descentralizada & Centralizada & Descentralizada \\
\hline $\begin{array}{r}\text { Ambiente en } \\
\text { sector privado }\end{array}$ & $\begin{array}{l}\text { Informalidad y } \\
\text { confianza }\end{array}$ & $\begin{array}{l}\text { Semiformalidad, } \\
\text { falta de confianza } \\
\text { y desprecio por } \\
\text { el rule of law }\end{array}$ & Formal y legal \\
\hline $\begin{array}{l}\text { Cultura de } \\
\text { evaluación }\end{array}$ & $\begin{array}{l}\text { Serpientes y } \\
\text { escaleras }\end{array}$ & "Gotcha" & $\begin{array}{l}\text { Aprendizaje y } \\
\text { mejora }\end{array}$ \\
\hline
\end{tabular}


En la siguiente sección, contemplaremos algunos de los factores que entran en juego para impedir el proceso de realineamiento de las funciones y la armonización de la misión, los valores del sector público, el ambiente competencial y la capacidad operacional en los países en desarrollo.

\section{¿Por qué el camino hacia la reforma permanece siendo un campo de sueños?: consideraciones prácticas}

Señalamos que en la mayor parte de los países en desarrollo los sectores públicos requieren una reestructuración importante. El progreso hasta la fecha de tales reformas ha sido desigual. Un número de factores han impedido el progreso de reforma en grados que varían en diversos países.

\section{Factores políticos}

La estabilidad política es esencial para el éxito de cualquier reforma. En América Latina, y en otras economías con planificación central, el surgimiento de la gobernabilidad democrática y de las libertades políticas condujo a un cada vez mayor interés en la mejora de la actuación del sector público y la descentralización de los servicios públicos locales se vio como un elemento importante de esta reforma. En América Latina, el desencanto con la dictadura militar y las dictaduras de varios tipos ha llevado a la creación de una cultura política que pone mayor interés en la toma de decisiones descentralizada para prevenir una vuelta al pasado. En China, la descentralización se contempló como un medio para la cohesión social, un crecimiento más rápido de la economía y una conservación del liderazgo del partido comunista en el gobierno. La política bloquea la reforma en otros países. En Indonesia, los padres de la Constitución claramente pretendían ser un país centralizado y unitario y dispusieron reglas en contra del establecimiento de "Estados dentro de Estados". Estas preocupaciones por la unidad política han dominado el diseño de las instituciones. Las bien enraizadas funciones del servicio militar y civil en los asuntos políticos, con una fuerte creencia en la dirección y el control desde el centro, han sostenido la centralización de la responsabilidad. El nombramiento de gobernadores y alcaldes también fortalece la centralización y limita la autonomía local. Sin embargo, en años recientes, el desarrollo social y la prosperidad económica, al igual que las preocupaciones por mejorar la provisión de servicios públicos, están produciendo un grado de acomodo para las instituciones descentralizadas.

En Pakistán, la inestabilidad política y los intereses feudales han contribuido a poner a un lado los dictados de la Constitución y han introducido 
un sistema de gobernabilidad centralizado. Pakistán ha estado sujeto a una dictadura militar durante la mayor parte de su existencia (25 de 52 años) y la toma de decisiones fue aún más centralizada por estos regímenes. Durante estos períodos se permitieron actividades políticas, influencias feudales dominaban el sistema político y estas influencias favorecieron bien una centralización o provincialización de la autoridad. En las áreas rurales de Sind y Bacholistan y, en menor medida, en las áreas rurales de Punjab y en las provincias de NWFP, los señores feudales no permitían la efectiva participación política. La centralización o provincialización de la autoridad permite que los señores feudales dominen la política en los niveles federales y provinciales. Un sistema centralizado permite a estos señores feudales tener un control más efectivo del que resultaría posible bajo un sistema descentralizado en el que el sector urbano tendría una voz más dominante. Para atrincherar aún más a los señores feudales, bajo el liderazgo del anterior Primer Ministro Ms Bhutto en 1994, los gobiernos locales se disolvieron en todas las áreas metropolitanas y no se lograron reinstaurar ni siquiera cuando en 1996 el Tribunal Supremo de Pakistán falló que tal práctica contravenía la ley. Concesiones a miembros de las legislaturas nacionales y provinciales para el desarrollo de proyectos estuvieron en práctica hasta 1997, y pudieron haber actuado en contra del desarrollo de los gobiernos locales, ya que estos miembros disfrutaron de un mayor grado de autonomía en la ejecución de proyectos a falta de un sistema que funcionara bien a nivel del gobierno local.

\section{Factores burocráticos}

Muchos países en África y Asia comparten una herencia colonial común. Los sistemas coloniales británico, danés y francés instituyeron un sistema de control burocrático para alcanzar la mayor eficiencia de los objetivos coloniales en un Estado depredador. El sistema creó un núcleo de élite funcionarial que estaba muy bien educada y, en su mayor parte, dedicada a servir a los gobernantes coloniales. Su lealtad a los gobernantes y su separación del ciudadano común se contemplaba debidamente permitiéndoles acceso preferencial a todos los servicios públicos, a través de instituciones elitistas y asegurándoles seguridad financiera a través de un sistema de compensaciones en metálico y de concesión de tierras. Así, los países colonizados como India, Kenia, Pakistán e Indonesia heredaron los regímenes funcionariales que estaban altamente centralizados, aparentemente eficientes, responsables y profesionales, pero completamente desvinculados de la población local. Estos regímenes se han mantenido resistentes al cambio, especialmente a traer la responsabilidad por resultados. Por ejemplo, después de la independencia, en Indonesia, el funcionariado con el tiempo se convirtió en un compañero político activo 
con la milicia en el gobierno del país. Los dos compañeros veían el control centralizado como el elemento clave para mantener este país, de 14.000 islas, unido. Sin embargo, con el tiempo descubrieron que el grado inicial de descentralización no era sostenible y, por tanto, que era necesario un importante grado de autonomía para los gobiernos locales, a la vez que mantener una débil estructura de los gobiernos provinciales, para mejorar la provisión de los servicios públicos. Un cambio gradual hacia el control local (localización) se ve, por tanto, que no supone ninguna amenaza a la unidad nacional y a la preservación de una dirección y un control orientado a un régimen burocrático.

\section{Factores institucionales}

Los factores institucionales también impiden la efectiva descentralización y adopción del ROME. Las instituciones tradicionales y el mecanismo de gobernabilidad y responsabilidad con el tiempo han ido desapareciendo, pero no se han remplazado por nuevas instituciones. En cambio, todo papel penetrante del Estado ha retrasado la mirada crítica a las políticas y las instituciones públicas. Hay casi un total monopolio del gobierno en las instituciones de pensamiento crítico y de medios de comunicación en muchos países. Toda visión crítica de los programas y las políticas del gobierno invita a una retirada del gobierno. En Pakistán, un autogobierno rural funcionó bien en anteriores años de su independencia. Este sistema se abandonó en favor de un sistema más centralizado que resultó en la denegación del acceso a los servicios básicos de la población rural. Mientras que la falta de capacidad institucional se citó como una de las razones de la disolución del sistema participatorio, el nuevo sistema dejó a la mayoría de los ciudadanos sin voz y participación y sin acceso a servicios públicos básicos. Por otro lado, Indonesia está ahora alimentando un autogobierno en áreas rurales a través del desarrollo de los pueblos y los programas de concesiones para países pobres (ver Shah, 1996).

Otro aspecto importante de los factores institucionales es la filosofía de los ciudadanos hacia el gobierno ¿Ve la gente en general (políticos, burocráticos, empleados públicos en general, el público/el votante) al sector público como aquel en el que uno realiza un servicio por una justa compensación o, más bien, como una posición para explotar las ganancias personales? Varios estudios sugieren que la percepción pública prevalente referente al sector público, especialmente en el sur de Asia y África, tiende a defender esta última visión y los ciudadanos tienden a asociar el sector público con un rol depredador.

En contra de los malentendidos habituales, el éxito de las políticas

de descentralización requiere de forma esencial un gobierno fuerte receptivo y responsable a nivel nacional, al igual que el éxito de la 
gobernabilidad centralizada depende esencialmente de un campo de oficinas del gobierno central receptivas, responsables y competentes. Ésta es la menos entendida "paradoja de la descentralización (reajustes)". Esto sugiere que la centralización requiere un mayor grado de capacidad y competencia institucional local y una mayor sofisticación e integridad de la dirección de la información pública, financiación, contabilidad y sistemas de auditorías, que las que se requieren bajo un sistema descentralizado. Por otro lado, el éxito de las estructuras descentralizadas depende de un ambiente con un nivel habilitante mayor y una mayor participación ciudadana y menos nivel en la capacidad institucional local y en la red de información tal y como se confirma por la experiencia colombiana (ver Fiszbein, 1995). Sin duda, la capacidad institucional local y la red de información son importantes, pero pueden solventarse, tomando prestada tal capacidad de fuentes internas y externas al menos durante las primeras fases de la descentralización, siempre que prevalezca un ambiente con un nivel habilitante más alto.

\section{Participantes externos}

En los países en desarrollo, algunos participantes externos pueden también de forma poco inteligente impedir el desarrollo de un sector público descentralizado, receptivo y responsable. Una multitud de factores contribuyen a este desarrollo. Primero, un sistema jerárquico centralizado reduce los costes transaccionales de la ayuda extranjera y agranda la zona de confort para los participantes externos en términos de dirigir la utilización de sus fondos para propósitos intencionados. En segundo lugar, algunos participantes externos se han preocupado con la actuación: respecto de los ingresos de los países en vías de desarrollo (llamada "movilización de recursos"). Tales preocupaciones pueden conducir a mayores burocracias centralizadas que prestan poca atención a la eficiencia en la provisión de los servicios públicos. Por ejemplo, en Pakistán, las mínimas mejoras en la actuación de los gobiernos respecto de los ingresos han venido acompañadas en el pasado por un permanente deterioro de la calidad y cantidad de los servicios públicos. En tercer lugar, los sistemas centralizados son más propicios a carecer de una agenda política interna, debido a la falta de participación ciudadana y dependen más del consejo externo sobre la reforma política. Esto conduce típicamente a rápidas fijaciones políticas con una reforma poco sostenida.

\section{Convirtiendo los sueños en realidad: acertando con las instituciones}

La adhesión a principios del federalismo y de ROME o "acertando en los precios" o incluso "acertando en las reglas del juego" tal y como se discutió anteriormente, es una condición necesaria pero no suficiente para 
el éxito de la toma de decisiones descentralizada. Se necesitan instituciones

formales e informales para asegurar que todos los participantes del juego se adhieren a una serie de reglas de base acordadas y se afronta adecuadamente la conducta desviada. En los siguientes apartados discutimos aspectos seleccionados de esta consideración.

\section{Instituciones y procesos de coordinación intergubernamental}

Los países federales requieren tanto instituciones formales como informales de coordinación intergubernamental. En algunos países federales se minimizan las áreas de conflicto potencial entre los diferentes niveles del gobierno a través de la clara separación de las responsabilidades nacionales y subnacionales (el llamado modelo de capas de tarta de federalismo, tal y como se ha puesto en práctica en Australia, Canadá, India y Pakistán y los dos niveles interactúan a través de reuniones de funcionarios y ministros (federalismo ejecutivo) y en Australia, India y Pakistán a través de unilateralismo federal. Algunos países ponen más interés en una respuesta común a través de compartir y ejecutar conjuntamente tareas, tal y como es el caso en Alemania, un país federal y la República de Suráfrica, un país pseudofederal. En estos países, además de federalismo ejecutivo, las Cámaras altas de los Parlamentos (Bundesrat y el Consejo de Provincias) juegan un papel clave en la coordinación intergurbernamental. En países con responsabilidades que se entrecruzan (el llamado modelo de tarta de mármol de federalismo), tales como Estados Unidos y Brasil, el lobby estatal del Congreso y las relaciones interestatales sirven a funciones de coordinación. En China, donde las preocupaciones por el crecimiento han impuesto una estructura de federalismo en un país unitario, los jefes/gobernadores del partido comunista local ejercen una moderada influencia en la orientación del Consejo Estatal, que si no, sería monolítica.

Las disposiciones constitucionales per se también pueden proporcionar influencia de coordinación. Por ejemplo, en algunos países federales, las previsiones constitucionales requieren que toda la legislación reconozca que en último término el poder está en manos del pueblo. Por ejemplo, toda la legislación en Canadá debe ser acorde con la Carta de Derechos Canadiense. En Suiza, que es una Confederación por ley, pero un país federal en la práctica, los cambios legislativos más importantes requieren la aprobación por referéndum. En Suiza, también existe una fuerte tradición de coordinación a través de iniciativa de consenso de los cantones.

\section{Instituciones de responsabilidad}

Las instituciones de responsabilidad son la clave para el éxito de la toma de decisiones descentralizada. Esto vincula a las instituciones y mecanismos para la voz y salida de los ciudadanos, normas y redes de 
compromiso cívico ("capital social" de acuerdo con Putnam, 1994), consenso social (Williamson, 1994, y Weingast, 1993), la preservación del instinto de preservación de un "bandido estacionario" que monopoliza y racionaliza los robos en forma de tributos (Olson, 1993), la responsabilidad de los jueces, la responsabilidad vertical y horizontal. La voz y la salida del ciudadano requieren instituciones de participación democrática, y reglas de responsabilidad para los cargos electos. Los orígenes y el éxito de los programas de descentralización en Latinoamerica se reconducen a las tradiciones democráticas que emergieron en el continente a finales de los 80. En Filipinas, la reciente legislación aprobada del gobierno local mientras que otorga poder (empowerment) a estos gobiernos les ha proporcionado elecciones regulares y la revocación de los funcionarios electos por infringir la confianza pública (ver República de Filipinas Ley no 7.160, Código del Gobierno Local, 1991). Mientras las normas y las redes de compromiso cívico se desarrollan razonablemente bien en las sociedades tradicionales precoloniales fundadas en muchos países en desarrollo tales como el Panchayat Raj en la India prebritánica, estas instituciones se desvanecieron bien bajo el gobierno colonial o seguidamente bajo estructuras de gobernabilidad burocrática centralizadas. El resultado final ha sido el aumento del oportunismo y la desconfianza social, culminando en sociedades disfuncionales cuando fallaban las instituciones de gobernabilidad formal. Los fiascos en el desarrollo africano y surasiático tienen esta cuestión de fondo en común. El consenso social respecto de los derechos económicos y políticos también conduce a la responsabilidad en todos los niveles. De acuerdo con Weingast (1993), este consenso no requeriría de ninguna expresión formal, sino que funcionaría siempre que la mayoría de la gente comparta una creencia común en cuanto a los límites de la intervención gubernamental y estén dispuestos a custodiar esos límites retirando su apoyo a un gobierno que no consigue ajustarse a ellos (ver Weingast, 1993: 306). Los instintos de conservación de un "bandido estacionario" también respetan la responsabilidad (ver Olson, 1993). Esto se debe a que el "bandido estacionario" refuerza su asidero del poder, mientras que los resultados económicos sean consistentes y los ciudadanos vean mejorado su bienestar. Esto explica, en parte, el éxito de los Tigres Asiáticos y el fallo de algunos regímenes Sur/Surasiáticos. Estos últimos regímenes eran controlados por "bandidos errantes", cuya principal finalidad era mantener el botín para rellenar sus cuentas del banco suizo y después desaparecer a un paraíso extranjero.

La responsabilidad de los jueces fortalece la credibilidad de los compromisos públicos. Esto resulta especialmente importante para economías en transición, donde las leyes marco sobre derechos de propiedad, propiedad legal de sociedades y control, quiebra y control financiero no se han desarrollado completamente. Aún más interesante 
resulta el hecho de que la responsabilidad es mucho más difícil de hacer cumplir en una democracia parlamentaria que en un sistema democrático que respeta la separación del poder legislativo y contrarresta la responsabilidad de los jueces reformando la legislación - juego al que se jugó hasta el infinito en Pakistán para minar una Constitución federal descentralizada. La responsabilidad de los jueces se ve aún más comprometida bajo el estilo británico de organización funcionarial, como en India y Pakistán, donde los comisionados divisionales y por distritos ejercen simultáneamente poderes ejecutivos, legislativos y judiciales. Tal y como se dijo por Montesquieu (1970: 397), ésa es una situación madura para el abuso de poderes, ya que

“... Cuando los poderes legislativo y ejecutivo se unen bajo un mismo cuerpo de magistrados, no puede haber libertad; ... de nuevo, no hay libertad, si el poder judicial no se puede separar del legislativo y el ejecutivo."

\section{Canales tradicionales de responsabilidad}

Se deberían fortalecer las funciones de auditoría, inspección y control, ya que tienden a ser bastante débiles en economías en desarrollo y en transición. Se debería otorgar mayor autoridad y autonomía al auditor general en el ejercicio de su mandato. Al mismo tiempo, se puede establecer un caso para reducir las restricciones del proceso de planeamiento central en países en desarrollo. Los planes centrales conducen a una centralización de la autoridad, una reducción de la flexibilidad, una innovación y autonomía a nivel local y retrasos en la actividad del sector privado. De forma más específica, a medida que la responsabilidad fiscal se descentraliza al Estado y a los niveles locales, resultaría más beneficioso crear la capacidad institucional para el préstamo local, de forma que se confíe más en prestar y menos en la concesión de capitales a proyectos financieros de capital. Los ejemplos incluyen consejos prestamentistas o sociedades de financiación municipal.

\section{Vigilancia de los gobiernos locales: libertad y responsabilidad dentro de las fronteras}

La dirección y la vigilancia de los gobiernos locales es un área de preocupación del mismo modo en países federales que en países unitarios. Por ejemplo, la Constitución de la República de Suráfrica de 1996 Sección 139(1) (b) — dispone la disolución del gobierno local en supuestos 
de fracaso y posibilidad de una desbandada del gobierno local en caso de que no consiga: 1) "mantener los estándares nacionales o alcanzar los estándares mínimos de servicio"; 2) "prevenir acciones perjudiciales para los intereses de otra municipalidad o, de la nación como un todo", y 3) "mantener la unidad económica". Más aún, proporciona la posibilidad de contener las cuotas de impuestos y transferencias en caso de no cumplir con el esfuerzo tributario — Sección 227(2) —. El alcance de las obligaciones constitucionales, en lo que se refiere a estas provisiones, requiere una importante y superior evaluación de la capacidad a nivel nacional y provincial. Las medidas de evaluación que pueden servir de apoyo en esta vigilancia incluyen el requisito de la auditoría anual comercial societaria de los gobiernos locales; medición de la capacidad físcal utilizando un patrón común, por ejemplo, la igualación de los impuestos municipales; un mayor énfasis en fórmulas de concesiones sobre proyectos de concesiones en transferencias provinciales-locales; mayor énfasis en la asociación de la sociedad civil-privada-pública en la provisión pública; encuestas de opinión acerca de los estándares del servicio y la satisfacción ciudadana; rankings del cumplimiento de los gobiernos locales basados en outputs, resultados y satisfacción ciudadana.

\section{Algunas lecciones para los países en desarrollo}

Las siguientes lecciones importantes sobre las reformas de la gobernabilidad en los países desarrollados pueden derivarse de una revisión de las experiencias pasadas.

- La evolución institucional global se ha quedado atrás con el ritmo que ha tomado la globalización, haciendo, así, a los países en desarrollo más vulnerables frente a los deseos de los mercados globales. El vacío creado por la globalización en la regulación internacional y la vigilancia tiene consecuencias económicas y sociales adversas para la mayoría de las naciones en desarrollo. Se requiere una atención urgente para desarrollar y/o adaptar las instituciones globales y los regímenes para cubrir este vacío. Mientras tanto, puede que los países en desarrollo tengan que recurrir "fijar las ruedas" del mercado global para limitar los golpes externos.

- Desarrollo de las estrategias nacionales para la gestión del riesgo económico y social es esencial para limitar los fallos de la globalización. La gestión del riesgo económico incluye políticas para mantener un valor de red positivo para el gobierno y una estructura de regulación apropiada para el sector privado y para las operaciones 
financieras del mercado. La gestión del riesgo social requiere un desarrollo acelerado de las redes de seguridad social.

- Una revisión periódica de las tareas jurisdiccionales es esencial para realinear las responsabilidades con una realidad económica y política cambiantes. Con la globalización y la localización, es probable que el papel directo del gobierno nacional en la estabilización y el control macroeconómico desaparezca con el tiempo, pero se espera que aumente su papel en la protección social, la educación, el adiestramiento y las habilidades para resaltar, y en la coordinación y la vigilancia, a medida que los regímenes y los gobiernos subnacionales asumen funciones cada vez más importantes en algunas de sus áreas de responsabilidad tradicional. Los sistemas constitucionales y legales y las instituciones deben ser favorables a ajustes ocasionales para adaptarse a las circunstancias cambiantes.

- Ambiente favorable para la descentralización; por ejemplo, las instituciones de participación ciudadana y responsabilidad deben ser objeto de reforma en cualquier reforma importante de los sistemas fiscales. Estos elementos no han sido afrontados suficientemente en la mayor parte de los intentos de reforma. Son esenciales, en una reforma de la gobernabilidad en países en desarrollo, cambios en la cultura burocrática para implantar la responsabilidad por resultados. La experiencia demuestra que la burocracia nunca se reforma a sí misma y, por tanto, construir un compromiso político, un apoyo es esencial para introducir el ROME en estos países.

- La reforma del funcionariado es esencial para lograr el éxito del programa de descentralización. Tal reforma debe asegurar que el poder central no tiene nada que decir de forma directa en el reclutamiento y en la promoción de los funcionarios, más que vigilar que se alcanzan los estándares de transparencia y justicia en los niveles subnacionales y que los sueldos de los servicios subnacionales deben ser competitivos con el gobierno central. Más aún, la estructura funcionarial de incentivos debería recompensar la orientación del servicio y de la actuación y desalentar la dirección y el control y la búsqueda de rentas. Esto se puede alcanzar por medio de contratos de actuación, una cultura de "quedarse con ello", el reconocimiento de habilidades especializadas y sistemas de evaluación que unen la actuación, las recompensas y la presupuestación.

- La capacidad administrativa tradicional importa, pero no debería considerarse como un impedimento a la descentralización. La capacidad administrativa para desarrollar y mantener las prácticas organizacionales modernas tales como el presupuestar, la auditoría y los sistemas de contabilidad es, sin duda, importante, pero no debería considerarse como una barrera a la descentralización, siempre que se asegure la participación ciudadana y la transparencia en la toma de 
decisiones. Esto se debe a que la capacidad técnica puede tomarse prestada de los niveles gubernamentales superiores de apoyo y de otros sitios.

- La descentralización asimétrica, tal y como se preveía en el Programa de Descentralización de Indonesia y bajo las Ordenanzas del Gobierno Provincial y Local en Pakistán, ofrece una interesante aproximación a la descentralización. Sin tomar en consideración la disponibilidad de ayuda de los niveles gubernamentales superiores, la falta de capacidad institucional nunca debería considerarse como una excusa para no descentralizar. En cambio, puede desarrollarse un programa objetivo de descentralización que reconoce la naturaleza y el tipo de gobierno local, cuya clientela y capacidad fiscal, puede ser desarrollada y se les puede asignar a varios gobiernos locales poderes diferenciados, tomando en consideración los factores arriba mencionados, tal y como se hizo en el pasado en Pakistán, y de forma más sistemática en Indonesia graduando cada gobierno local.

- Una importante separación de las decisiones respecto del gasto y de los impuestos conduce a una falta de responsabilidad en el sector público. En Méjico, Sudáfrica y Pakistán, los ingresos federales compartiendo transferencias financian casi el $99 \%$ de los gastos en algunas provincias. Esta separación entre las responsabilidades de los impuestos y los gastos ha llevado a problemas de responsabilidad en los niveles provinciales. Si se produjerá tal separación, merecería la pena examinar el papel de las transferencias de bloqueo condicionales (condicionales respecto de los estándares de servicios y de acceso a tales servicios y no condicionales de los gastos) y de la evaluación para realzar la responsabilidad.

- Transferencias intergubernamentales en los países en desarrollo minan la disciplina fiscal y la responsabilidad, a la vez que crean dependencias en las transferencias que provocan una lenta estrangulación económica de las regiones fiscalmente desaventajadas. Por otro lado, las transferencias intergubernamentales adecuadamente desarrolladas pueden potenciar la competencia por el abastecimiento de bienes públicos, armonización fiscal, responsabilidad de los gobiernos infranacionales e igualdad regional. Una guía sustancial teórica y empírica en el diseño de estas transferencias está ya disponible. El diseño de estas transferencias debe ser sencillo, transparente y consistente con sus objetivos. La experiencia de Indonesia ofrece importantes ideas en el diseño de concesiones. Por ejemplo, las concesiones de educación y salud utilizan indicadores simples y objetivamente cualificables en la asignación de fondos y condiciones, ya que la elegibilidad continuada de estas concesiones enfatiza los objetivos estándar respecto del acceso a estos servicios. Por otro lado, las concesiones de Indonesia para los sueldos del sector público constituyen un ejemplo representativo de un 
diseño no tan pensado, ya que introduce incentivos para el mayor nivel de empleo público en los niveles subnacionales.

- El papel de las transferencias fiscales de potenciar la competencia para el abastecimiento de bienes públicos no debería pasarse por alto. Por ejemplo, las transferencias para salud básica y educación primaria podrían hacerse disponibles para el sector público y el sector privado sin ánimo de lucro sobre la misma base, utilizando como criterios los criterios demográficos de la población a la que se sirve, la edad escolar de la población y la matriculación de estudiantes etc. Esto promovería la competencia y la innovación, ya que tanto las instituciones públicas como las privadas competirían para obtener financiación pública. Chile permite que los colegios católicos accedan a la financiación de la educación pública. Las provincias canadienses permiten a los residentes individuales elegir entre colegios públicos o privados para la obtención de dólares sobre el impuesto de propiedad. Tal opción ha introducido fuertes incentivos para que los colegios públicos y privados mejoren sus actuaciones y sean competitivos. Tales opciones de financiación resultan especialmente atractivas para proporcionar mayor acceso a los servicios públicos en las áreas rurales.

- Las reglas fiscales acompañadas por consejos intergubernamentales/comités "guardianes" proporcionan una estructura útil para la disciplina fiscal y la política fiscal de coordinación. En este contexto, uno puede extraer de las experiencias de los países industriales "reglas de oro", las directrices del tipo de Maastricht y "directivas de presupuesto común" para desarrollar directrices específicas de un país. Para asegurar el cumplimiento voluntario de estas directrices, se debe desarrollar una estructura institucional apropiada. La transparencia de los procesos presupuestarios y de las instituciones, la responsabilidad frente al electorado y la disponibilidad general de datos comparativos de posiciones fiscales de todos los niveles del gobierno fortalece aún más la disciplina fiscal.

- La integridad y la independencia del sector financiero contribuye a la prudencia fiscal en el sector público. Para asegurar tal integridad e independencia, la propiedad y el acceso preferencial al sector financiero no deberían estar disponibles para cualquier nivel del gobierno. En un ambiente así, los mercados de capital y las agencias de calificación de valores proporcionarían una efectiva disciplina de la política fiscal.

- Para asegurar la disciplina fiscal, los gobiernos a todos los niveles deben enfrentarse a las consecuencias financieras de sus decisiones. Esto es posible si el gobierno central no frena la deuda local y estatal y el banco central no actúa como prestamista, como último recurso, del gobierno central.

- La existencia de normas societarias y consenso sobre los papeles de los diversos niveles de gobierno y límites a sus autoridades 
es vital para el éxito de la toma de decisiones descentralizada. En

ausencia de tales normas y de tal consenso, los controles centrales directos no funcionan y el juego intergubernamental lleva a constituciones disfuncionales.

- La descentralización impositiva es un requisito previo para el acceso a los mercados de crédito subnacionales. En países con sedes tributarias altamente centralizadas, el acceso no restringido a los mercados de crédito por los gobiernos infranacionales supone un riesgo para las políticas de macro estabilización del gobierno nacional, al anticipar el sector privado un alto grado del gobierno se salvaría en el caso de que ocurriera un fallo, y no descuenta los riesgos de tal prestación adecuada.

- Puede necesitarse ayuda institucional de mayor nivel para financiar proyectos de capital local. Esta ayuda puede adoptar la forma del establecimiento de sociedades de financiación municipal dirigidas en base a principios comerciales para reducir el coste de tomar prestado, utilizando una calificación superior de los créditos del nivel superior del gobierno y agencias de calificación municipal para determinar el valor de los créditos.

- La mejor forma de mantener un mercado interno común es por medio de garantías constitucionales. En los países en desarrollo, los gobiernos nacionales han fallado típicamente en esta función.

- Por último, en contra de una concepción errónea de una mayoría, el ambiente institucional de un país en desarrollo requiere un mayor grado de descentralización y una implementación mucho más rápida del $R O M E$, de la requerida para un país industrializado. Para un trabajo eficiente de una burocracia centralizada se necesitan la recogida de información avanzada y las redes de transmisión, un funcionariado eficiente y dedicado, e instituciones bien desarrolladas de participación ciudadana y responsabilidad. Esto es posible en el escenario del ambiente de un país desarrollado. Un ambiente de sector público más primitivo resulta más adecuado para una forma de gobernabilidad descentralizada que se basa en reponsabilidad por resultados de abajo arriba. Esto se debe a que los requisitos de información y los costes de transacción se minimizan trayendo la toma de decisiones más cerca de los ciudadanos que se ven afectados por esas decisiones. Esa proximidad sirve también para potenciar una participación mejor, una preferencia acorde con los servicios públicos, transparencia y una mayor responsabilidad. 


\section{Apuntes}

* Autorizado pelo Centro de Publicaciones del Instituto Nacional de Administración Pública, Madri, Espanha.

** Presentado ante la Conferencia Internacional sobre la Administración Financiera del Sector Público: Federalismo Fiscal y Descentralización, celebrada en Madrid, 14 al 16 de junio del año 2000. El autor da las gracias a James Hamilton, FMI, por sus comentarios. Los puntos de vista puestos de manifiesto en este trabajo son sólo aquellos del autor y no deben atribuirse al grupo Banco Mundial. Dirijan todos los comentarios a Anwar Shah, World Bank, Room H3-343, 1818 H Street, N, W., Washington, DC 20433, USA; Teléfono 202-473-7687; Fax 202-522-3124; E-mail: ashah@ worldbank.org.

\section{Bibliografía}

Afonso Rodrigues, José Roberto; Lobo, Thereza. (1996), Fiscal Decentralization and Participation in Delayed Democratic Experiences, Processed, October.

Alam, Shahid. (1996), Corruption and Countervailing Actions in Pakistan, North - Eastern University. Processed.

BLAIR, Harry; HANSEN, Gary. (1994), "Weighing in the Scales of Justice”, USAID Programs and Operations Assessment Report, nn 7, Arlington, VA: USAID Development Information Services Clearinghouse.

BLAIR, Harry. (1996), Supporting Democratic Local Governance: Lessons from International Donor Experience - Initial Concepts and Some Preliminary Findings. American Political Science Association Meetings, San Francisco, California - 29 August - 1 September. Processed.

Boadway, Robin; Roberts, Sandra; Shah, Anwar. (1994), "The Reform of Fiscal Systems in Developing and Emerging Market Economies: A Federalism Perspective”, Policy Research Working Papers Series, no 1259, Washington, DC: World Bank.

BomfiM, Antulio; Sнан, Anwar. (1994), "Macroeconomic Management and the Division of Powers in Brazil: Perspectives for the 1990s", World Development, vol. 22, no 4, 533-542.

Courchene, Thomas; (s/d), "Macrofederalism", en Sнah (1996), Macrofederalism, World Bank, Washington, DC.

(1993), Globalization, Institutional Evolution and the Australian

Federation. Processed.

Сrook, R., Manor, James. (1994), Enhancing Participation and the Institutional Performance: Democratic Decentralization in South Asia and West Africa, London: Overseas Development Administration.

Cukierman, Alex; Webb, Steven; Neyapti, Bilin. (1992), "Measuring the Independence of Central Banks and Its Effect on Policy Outcomes", World Bank Economic Review 6 (3), 353-398. 
DeININGer, Klaus; Squire, Lyn. (1996), "Measuring Income Inequality: A New Data Base",

The World Bank Economic Review 10(3), 565-591.

DRUCKER, Peter. (1986), The Changed World Economy. Foreign Affairs (spring), 3-17.

EHDAIE, Jaber. (1994), "Fiscal Decentralization and the Size of Government", Policy Research Working Papers Series, no 1387, World Bank, Washington, DC.

EID, Florence. (1996), Agency Theory, Property Rights, and Innovation in the Decentralized Public Sector. Department of Urban Studies and Planning. MIT, Cambridge, Mass.

Garman, Christopher; Haggard, Stephen; Willis, Eliza. (1996), Descentralization in Latin America, University of California, San Diego. Processed.

Gurgur, Tugrul; Shah, Anwar. (1999), Causes of Corruption. An Empirical Analysis, World Bank. Processed.

Hart, Oliver. (1995), Firms, Contracts and Financial Structure, Oxford: Clarendon Press. Held, David; Mcgrew, Anthony; Goldblatt, David; Perraton, Jonathan. (1999), Global Transformations. Politics, Economics and Culture, Stanford University Press, Stanford, California.

Heluiwel, John F. (1999), Balanced Growth: The Scope for National Policies in a Global Economy, International and Development Studies Working Paper, Queen's University.

Heymans, Chris. (1996), Democratization Through Decentralization: Some South African Observations. Processed.

Humplick, Frannie; Moint-Araghi, Azadeh. (1996), “Optimal Structures for Decentralized Provision of Roads", Journal of Infraestructure Systems, September, 127-138.

HutHER, Jeff; SHAH, Anwar. (1998), "A Simple Measure of Good Governance and its Application to the Debate on the Appropiate Level of Fiscal Decentralization", World Bank Policy Research Paper Series, no 1894, March, Washington, DC: World Bank.

KetTL, Donald. (1997), "The Global Revolution in Public Management: Driving Themes, Missing Links”, Journal of Policy Analysis and Managament, vol. 16, ํㅜ 3, 446-462.

Krugman, Paul. (1995), Growing World Trade: Causes and Consequences Brooking Papers on Economic Activity, 327.62.

LANDON, Stuart. (1996), Education Costs and Institutional Structure, University of Alberta Department of Economics Research Paper, no 96-4, June.

LIPSEY, R. (1997), "Globalization, and National Government Policies: An Economist's View", en J. DunNing (ed.), Governments, Globalization, and International Business, Edward Elgar Press.

Manor, James. (1999), The Political Economy of Decentralization, The World Bank, Washington, DC.

MeEnaKSHISUndaram, S. S. (1996), Rural Development Through Decentralized Governance - An Indian Experience. Paper for the World Bank Conference on Environmentally Sustainable Development, September, 25-27.

Minogue, Martin; Pollidano, Charles; Hulme, David. (1999), Beyond the New Public Management. Changing Ideas and Practices in Governance, Edward Elgar: Northampton, MA, USA.

Montesquieu. (1970), "The Spirit of the Laws", en M. Curtis (ed.), The Great Political Theories. Disus/Avon Books: New York.

Olson, Mancur. (1993), "Dictatorship, Democracy and Development", American Political Science Review, vol. 87, ㄲo 3, 568-576.

Olowu, Dele; Sмоке, Paul. (1992), "Determinants of success in African Local Governments: Ari Overview", Public Administration and Development, vol. 12, 1-17.

Paul, Samuel. (1996), Decentralization and Demacracy. Processed.

PruD' homme, Remy. (1995), “On the Dangers of Decentralization”, The World Bank Research Observer, August, 201-210,

ReIcH, Robert. (1991), The World of Nations, New York: Alfred A. Knopf. 

NBER Working Paper\#5905, Cambridge: Mass.

. (1998), "Why Do More Open Economies Have Bigger Governments?", Journal of Political Economy, vol. 106, 997-1032.

RugGie, J. G. ( 1993), Territoriality and beyond, International Organization 41.

SAKNINI, Humam; JAMES, Steven; SHEIKH, Munir. (1996), Stabilization, Insurance and the Risk Sharing in Federal Fiscal Policy. Processed, Department of Finance, Ottawa.

ScHick, Allen. (1998), Why Most Developing Countries Should Not Try New Zealand Reforms?, World Bank. Processed.

Schulze, Gunther; Heinrich, G., Urspung, W. (1999), "Globalization of the Economy and the Nation State", The World Economy, vol. 22, no 3, May, 295-351.

SHAH, Anwar. (1998), "Balance, Accountability, and Responsiveness. Lessons about Decentralization”, The World Bank Policy Research Working Papers Series, no 2021, December. . (1998), "Fiscal Federalism and Macroeconomic Governance: For Better or For Worse?”, Police Research Working Papers Series, no 2005, November, World Bank, Washington, DC. . (1996), “A Fiscal Need Approach to Equalization”, Canadian Public Policy, XXII:2; 99-115.

(1996), "Fiscal Decentralization-an Elusive Goal? A Case Study of Indonesia and Pakistan Experience", en Bird, Richard y VALLENCourT, Francois (eds.) (1998), Fiscal Decentralization in Developing Countries Cambridge University Press: New York and London, 115-151.

Sнан, Anwar, (ed.). (1996), Macrofederalism, World Bank, Washington, D.C. Manuscript of a forthcoming book. . (1995), Fiscal Federalism In Pakistan, Challenges and Opportunities, World Bank, Washington, DC.

SHAн, Anwar et al. (1994), "Intergovernmental Fiscal Relations in Indonesia", World Bank Discussion Paper, no 239, Washington, DC: World Bank.

Sнан, Anwar. (1994), The Reform of Intergovernmental Fiscal Relations in Developing and Emerging Market Economies, World Bank, Washington, D.C.

SHEIKH, M. A., WinER, S. L. (1977), "Stabilization and Nonfederal Behavior in an Open Federal State: An Econometric Study of the Fixed Exchange Rate, Canadian Case", Empirical Economies, vol. 2, oㅡ 3, 195-211.

Sмith, Janet. (1997), "Government Reform in Canada", Public Administration and Development, vol. 17, 33-39.

SpaHn, Paul Bernd. (1997), Decentralized Government and Macroeconomic Control. Processed.

StRAnge, S. (1996), The Retreat of the State: The Diffusion of Power in the World Economy, Cambridge: Cambridge University Press.

TAnzI, Vito. (1996), "Fiscal Federalism and Decentralization: A Review of Some Efficiency and Macroeconomic Aspects", Annual World Bank Conference on Development Economics, 1995, World Bank, Washington, D.C., 295-316.

TER-Minassian, Teresa (1996), Borrowing by Subnational Governments: Issues and Selected International Experiences, International Monetary Fund, Washington, D.C.

Tsui, Kai-yuen. (1996), "Economic Reform and Interprovincial Inequalities in China", Journal ol Development Economics, vol. 50, 353-368.

Untted States Agency For International DeVelopment. (1997), Democracy and Governance Highlights, Washington, D.C.: US Government. 
WALKER, Basil. (1996), "Reforming the public sector for leaner government and improved performance: The New Zealand Experience", Public Administration and Development, vol. 16, 353-376.

Weingast, Barry. (1993), "Constitutions as Governance Structures: The Political Foundations of Secure Markets", Journal of Institutional and Theoretical Economics, 149, 286-311.

Whalley, John. (1999), Globalization and the Decline of the Nation State. Processed.

Williamson, Oliver (1994), "The Institutions and Governance of Economic Development and Reform", Proceedings of the World Bank Annual Conference on Development Economics, 171-197.

World BAnK. (1998), Results Based Management, Operations Evaluation Department. Processed.

Wunch, James. (1991), "Institutional Analysis and decentralization”, Public Administration and Development, vol. 11, 431-451. 


\section{Governando para obter resultados em um mundo globalizado e localizado}

Anwar Shah

Ano 52

Número 4

$\mathrm{O}$ artigo trata de três questões complementares relacionadas com a governabilidade nos países em desenvolvimento: a globalização, a localização e a gestão e avaliação orientadas à obtenção de resultados. A globalização, a revolução da informação e a localização estão exercendo grande influência na governabilidade econômica, tanto no mundo industrializado como no mundo em vias de industrialização. Com a globalização, fica cada vez mais evidente, que os "Estados-nação são demasiadamente pequenos para fazer frente a questões essenciais da vida e demasiado grandes para enfrentar questões menores". Os Estados-nação perdem com rapidez o controle de alguns setores que eram tradicionalmente objeto de controle e regulação, como o comércio exterior, as telecomunicações e as transações financeiras. Com a revolução da informação, os governos estão experimentando uma diminuição em sua capacidade de controlar o fluxo de bens e serviços, idéias e produtos culturais. A localização, num realinhamento com as expectativas de cidadãos cada vez mais informados e participativos, leva a uma aquisição de poder em certas áreas, uma vez que produz um fortalecimento das elites locais em outras áreas. A gestão e a avaliação orientadas à obtenção de resultados (Results Oriented Management and Evaluation - ROME) estão enfrentando a cultura burocrática e política, com o modelo do cliente-cidadão, e a responsabilização (accountability) com os resultados.

Este artigo analisa as potencialidades e os perigos associados ao impacto destas grandes mudanças na estrutura da governabilidade no século XXI. E ainda apresenta lições desta experiência para capitalizar estas importantes mudanças e produzir melhoria na governabilidade do setor público nos países em desenvolvimento.

\section{Gobernando para obtener resultados en un mundo globalizado y localizado Anwar Shah}

El artículo trata tres cuestiones complementarias relacionadas a la gobernabilidad en los países en desarrollo: la globalización, la localización y la gestión y evaluación orientadas a la obtención de resultados. La globalización, la revolución de la información y la localización están ejerciendo gran influencia en la gobernabilidad económica tanto en el mundo industrializado, como en el mundo en vías de industrializarse. Con la globalización, cada vez resulta más evidente que los "Estados-nación son demasiado pequeños para afrontar cuestiones esenciales de la vida, y demasiado grandes para afrontar cuestiones menores." Los Estados-nación pierden con rapidez el control de algunos sectores que eran tradicionalmente objeto de control y regulación, como el comercio exterior, las telecomunicaciones y las transacciones financieras. Con la revolución de la información, los gobiernos están experimentando una disminución en su capaciadad de controlar el flujo de bienes y servicios, ideas y productos culturales. La localización, en un realineamiento con las expectativas de ciudadanos cada vez más informados y participativos, lleva a una adquisición de poder en ciertas áreas, a la vez que se produce un fortalecimiento de élites locales en otras áreas. La gestión y la evaluación orientadas a la obtención de resultados (Results Oriented Management and Evaluation - ROME) están enfrentando a la cultura burocrática y política con el modelo del ciudadano-cliente, y la responsabilidad (accountability) con los resultados.

Este artículo analiza los potenciales y los peligros asociados con el impacto de estos grandes cambios en la estructura de gobernabilidad en el siglo XXI. Más aún obtiene lecciones de esta experiencia para capitalizar este importantísimo cambio y producir una mejora en la gobernabilidad del sector público en los países en desarrollo.

Anwar Shah es economista del Banco Mundia] 
Governing to get results in a globalized and located world

Anwar Shah

The article deals with three complementary questions related to governability in developing countries: the globalization, the localization and the management and evaluation oriented to results.

The globalization, the information revolution and the localization have great influence in the economic governability, as much in the industrialized world as in the world in industrialization ways.

With globalization, it is more evident that the "State-nations are too small to face the essential questions of life and too big to face less important questions". The State-nation quickly loses control of some sectors that were traditionally object of control and regulation, such as the foreign commerce, the telecommunications and the financial transactions. With the information revolution, the governments are trying a reduction in their capacity to control the flow of goods and services, ideas and cultural products. The localization, due to the realignment to the expectations of citizens more and more informed and participative, leads to an acquisition of power in certain areas, once it produces a strengthening of local elites in other areas.

The management and the evaluation oriented to results (Results Oriented Management and Evaluation - ROME) are facing the bureaucratic and politic culture with the customer/ citizen model, and the accountability with the results.

This article analyzes the potentialities and hazards associated to the impact of these huge changes in the governability structure in the $21^{\text {th }}$ century and presents lessons of this experience to capitalize those important changes and to promote improvements in the public sector governability in developing countries. 